\title{
The Intervention Effect in Late Archaic Chinese and Modern Mandarin
}

\author{
Aiqing Wang \\ University of Liverpool
}

\begin{abstract}
I investigate the Intervention Effect in Late Archaic Chinese (LAC) and modern Mandarin. In LAC, negation displays the Intervention Effect on wh-phrases. There are two types of $w h$-items that are subject to the Intervention Effect triggered by negation, namely, $w h$-arguments and $w h$-adverbials that are supposed to move to a lower focus position below the negation; and those that have the option to stay in situ. Due to the intervening negative barrier, these c-commanded wh-phrases have to rise to a higher focus position above the negation so as to circumvent the Intervention Effect. I propose that the Intervention Effect in LAC is a consequence of Q-binding as a feature movement of [wh], interacting with movement into the hierarchy of clause-internal positions driven by [Topic] or [Focus] features. By contrast, focus or quantificational phrases do not display the Intervention Effect in LAC. In modern Mandarin, focus phrases, but not negation or quantified structures, impose the Intervention Effect on wh-items; negation, but not focus phrases or quantified structures, imposes the Intervention Effect on temporal $w h$-adverbials. I also propound three obligatory requirements for the Intervention Effect to take place in LAC, namely, interrogativity of wh-items, the possibility of feature $w h$-movement, and a hierarchy of clausal positions. Although the Intervention Effect in LAC and modern Mandarin are triggered by different barriers, it always needs to meet the three requirements. Data from both LAC and Mandarin justify previous analyses regarding feature movement.
\end{abstract}

\section{Keywords}

the Intervention Effect, wh-phrases, Late Archaic Chinese, modern Mandarin, syntax

Studies in Chinese Linguistics, Volume 42, Number 1, 2021, 29-96 DOI: 10.2478/scl-2021-0002 (C) 2021 Aiqing Wang. Studies in Chinese Linguistics is published by Sciendo on behalf of T.T. Ng Chinese Language Research Centre, Institute of Chinese Studies, The Chinese University of Hong Kong. This work is licensed under the Creative Commons Attribution-NonCommercial-NoDerivatives 4.0 International License. 


\section{Introduction}

In this paper, I explore the Intervention Effect in Late Archaic Chinese (475-221 $\mathrm{BC}$; henceforth abbreviated as LAC) ${ }^{1}$ and modern Mandarin. I propose that feature movement is an obligatory requirement for the Intervention Effect to take place in LAC and modern Mandarin, so $w h$-constituents affected by the Intervention Effect should be permitted to undergo feature movement, instead of being restricted to covert phrasal movement. When an X-phrase (XP) [+wh] fronts, the preposing is introduced by overt movement, and then the $[+w h]$ feature is interpreted by feature movement. If an XP $[+w h]$ does not front, it is interpreted by feature movement. This research provides LAC and Mandarin data in support of previous analyses concerning feature movement.

The Intervention Effect - in the sense of Beck 1996a and Beck and Kim 1997 refers to the fact that a barrier may not intervene between a question existential operator (Q-operator) and a function variable bound by that Q-operator. Such a blocking effect applies to $w h$-in-situ (the stranded restriction of wh-constituents moving overtly), as well as $w h$-scope marking structures. Interrogatives in modern Mandarin could be introduced by $\mathrm{C}_{l-s p e c}$ or $\mathrm{C}_{m \text {-spec }}$, but this language pronounces all $w h$-phrases in the pre-wh-moved position. The sign of such a "superficial" $w h$-insitu language is the lack of the Intervention Effect in simple wh-questions.

The Intervention Effect in the sense of Kim 2002b, 2005, 2006 in modern Mandarin can be illustrated by Examples (1-4), which contain focus constructions. In the canonical order, the functional variable wh-in-situ is c-commanded by a focus phrase, which is a barrier for the interpretation (Q-binding); so, it has to be fronted to a sentence-initial position in order to circumvent the Intervention Effect. Kim (2002b) suggests that the core set of interveners that is cross-linguistically stable contains the focusing operators "only", "even", and "also". Example (2) contains a lian ... dou/ye construction semantically equivalent to even, which is generally assumed to rely on focus alternatives. The lian ... dou structure consists of a focus particle lian conveying additivity, as well as a maximality operator dou defining a scalar extreme; lian picks the entity and affirms that properties of that entity hold at the scalar extreme referred to by dou. The lian ... dou combination is almost interchangeable with lian ... ye, but the former imposes strong maximality/ exhaustivity, yet the latter simply confirms that some alternatives are true (Cheng 2009; Cheng and Vicente 2013). The scalar implicature is calculated

1 The primary sources of this paper are Peking University Corpus, Academia Sinica electronic database, and the Beijing Language and Culture University Corpus. The selected texts of these corpora represent a wide range of writings found in various time periods. In the LAC period, the corpora cover around 20 key books written by different authors and provide a considerable amount of discourses. 
using focus alternatives, and in Example (2), it is that for Lili to understand a certain book is the least likely thing to happen.

(1) a. ? Lili ye kan-le na-ben shu? ${ }^{2}$

Lili also read-ASP which-CL book

b. Na-ben shu Lili ye kan-le?

which-CL book Lili also read-ASP

'Which book did Lili, too, read?'

(2)
a. ?? Lian Lili ye kan de dong na-ben shu? even Lili also read DE understand which-CL book
b. Na-ben shu lian Lili ye kan de dong? which-CL book even Lili also read DE understand 'Which book could even Lili understand?'

(3)
a. ?* Zhiyou Lili kan-le na-ben shu? only Lili read-ASP which-CL book
b. Na-ben shu zhiyou Lili kan-le? which-CL book only Lili read-ASP

'Which book did only Lili read?'

(4) a. *Shui ye kan bu dong na-ben shu? who also read not understand which-CL book

b. Na-ben shu shui ye kan bu dong? which-CL book who also read not understand 'Which book could no one understand?'

(Kim 2002b: 626)

Example (4) involves a negative polarity item (NPI) shui ye 'who also' ('anyone'), which is morphologically composed of a wh-pronoun shui and the focus particle ye. Since cross-linguistically, an NPI is composed of an indefinite noun phrase (NP) (or a wh-pronoun) and an overt scalar focus particle expressing the meaning 'even; also', they can be analyzed as focus constructions, and NPI-licensing can be treated as a case of focus-sensitive quantification (Haspelmath 1997; Lahiri 1998; Kim 2006). Therefore, NPIs are barriers blocking the Logical Form (LF) movement of $w h$-in-situ to an operator position.

An NPI in LAC is merely constituted of an indefinite NP (5), while its counterpart in modern Mandarin may additionally contain an overt focus particle doulye meaning 'even; also', namely, shenme dou/ye meiyou. Alternatively, the counterpart of 無何有 wu he you in modern Mandarin can be meiyou shenme 'not. have what' without wh-fronting. ${ }^{3}$ The modern Mandarin counterparts of Example

2 According to an anonymous reviewer, Examples $(1 \mathrm{a} / 2 \mathrm{a} / 3 \mathrm{a} / 4 \mathrm{a})$ are acceptable.

3 Meiyou shenme in modern Mandarin could be either an NPI or an interrogative construction (Example [i]), because negation does not function as a barrier for Q-binding in modern Mandarin. 
(5) are in Examples $(6 \mathrm{a} / \mathrm{b})$ and $(6 \mathrm{c} / \mathrm{d})$. Following the same pattern, if the $w h$ indefinite is "who", the corresponding NPI in modern Mandarin is shui doulye 'who even/also' or meiyou shui 'not.have who', ${ }^{4}$ as in Examples (6e/f).

a. 何不樹之於 無何有 之 鄉? $\mathrm{He}$ bu shu zhi yu [[wu $\left[\mathrm{he}_{\mathrm{i}}\right.$ you $\left.\left.\mathrm{t}_{\mathrm{i}}\right]\right]$ zhi $\left.\mathrm{xiang}\right]$ ? why not plant it in not.exist what exist GEN place 'Why don't you plant it in a place where there isn't anything?' (Zhuangzi Xiaoyaoyou; Aldridge 2010: 26)

b. 而 遊 無 何 有 之 鄉 Er you $\quad\left[\left[w u \quad\left[h_{i}\right.\right.\right.$ you $\left.\left.t_{i}\right]\right]$ zhi xiang $]$ CONJ travel.around not.exist what exist GEN place 'And (I) traveled around a place where there wasn't anything.' (Zhuangzi•Yingdiwang)

(6) a. Weishenme bu ba ta zhong zai shenme dou/ye meiyou why not BA 3.OBJ plant in what even/also not.have de difang?

GEN place

'Why don't you plant it in a place where there isn't anything?'

b. Weishenme bu ba ta zhong zai meiyou shenme de difang? why not BA 3. OBJ plant in nothave what GEN place 'Why don't you plant it in a place where there isn't anything?'

c. Wo zai shenme dou/ye meiyou de difang youlan. I in what even/also not.have GEN place travel.around 'I traveled around a place where there wasn't anything.'

d. Wo zai meiyou shenme de difang youlan. I in not.have what GEN place travel.around 'I traveled around a place where there wasn't anything.'

According to Huang (1994), shenme can additionally be interpreted as a universal quantifier (Example [iia]) or an existential quantifier (Example [iib]), depending on the context.

(i) Zhangsan jia meiyou shenme?

Zhangsan home nothave what

'What is not there at Zhangsan's home?'

(ii) a. Wo shenme dou mai. I everything all buy 'I want to buy everything.'

b. Ta dagai mai-le shenme le. he probably buy-PERF something- PART 'He probably bought something.'

(Huang 1994: 171)

4 Interestingly, meiyou shui cannot adopt an interrogative interpretation (Example [i]) or at least sounds awkward without a contrast or context in some dialects of modern Chinese.

(i) ? Zhangsan jia meiyou shui?

Zhangsan home not.have who

(Intended: 'Who is not there at Zhangsan's home?') 
e. Shui dou/ye kan bu dong na-ben shu. who even/also read not understand that-CL book 'No one could understand that book.'
f. Meiyou shui kan de dong na-ben shu. not.have who read DE understand that-CL book 'No one could understand that book.'

According to Soh's (2005) generalization, in modern Mandarin, quantified structures and negation do not display the Intervention Effect on LF movement of nominal wh-phrases, but they do have such a blocking effect on LF interpretation of adverbial wh-phrases. Wh-arguments in Mandarin undergo covert phrasal movement. As illustrated earlier, nominal wh-phrases are immune to c-commanding quantifiers and negators for Q-binding between $w h$ and its licensing complementizer (Kim 2002b, Kim 2005, Kim 2006). With regard to wh-adverbials, however, the surface structure of Examples (7-8) suggests the presence of a quantifier-induced barrier and a negation-induced barrier (NIB). In Examples (7/8), the wh-variable "reason-why" cannot be bound by its Q-operator because of an intervening quantifier/negator, so it has to adopt the repair strategy by rising to a position across the quantifier/negator.
a. Ta
weishenme
chang ma
ta?
he why
often scold he
'What is the reason $x$ such that he often scolds/scolded him for $x$ ?'
b. * Ta chang weishenme ma ta?
he often why scold he

(Soh 2005: 146)
a. Zhangsan weishenme gongzuo?
Zhangsan why work
'Why does Zhangsan work?'
b. * Zhangsan bu weishenme gongzuo? ${ }^{5}$
Zhangsan not why work

5 If an emphasis is put on shenme within weishenme, Examples (7b) and (8b) seem grammatical. However, in that case, weishenme would adopt the rendering of 'purpose-why' (=wei-le shenme) and become a wh-nominal, which is distinct from the wh-adverbial weishenme 'reason-why' under discussion. The wh-adverbs under discussion here must be restricted to reason-why, which are quantifiers and thus subject to island effects. If weishenme is used as a purpose-why construct, which is encoded with nominal properties and immune from island effects, then the sentence is grammatical. Similarly, manner-how wh-adverbs are genuine quantifiers, yet method-/ instrumental-how of nominal elements is not subject to the Intervention Effect (Tsai 1994, Tsai 1996; Stepanov and Tsai 2008). It is notable that zenmeyang 'how' is base-generated within the VP, whereas weishenme is merged into the specifier of CP of the clause it modifies in the overt syntax. Zenmeyang and weishenme show asymmetries in their distributions in simplex sentences and long-distance extraction in complex sentences, which can be accounted for by the Empty Category Principle (ECP) defined by Chomsky $(1981,1986)$ and an assumption that immediate traces are not subject to the ECP (Lin 1992). 
c. Zhangsan weishenme bu gongzuo?
Zhangsan why not work
'Why does Zhangsan not work?'

Analogous to $w h$-nominals, the Q-binding of $w h$-adverbials is blocked by focus constructions, as in Example (9).
a. * Zhangsan
lian
[zhe-ben
shu] ye
weishenme kan?
Zhangsan
book also why
read
b. Zhangsan weishenme lian [zhe-ben shu] ye kan?
Zhangsan why even this-CL book also read
'Why does Zhangsan even read this book?'

Nevertheless, I notice that Soh's (2005) generalization concerning wh-adverbials only involves weishenme 'reason-why' in modern Mandarin, and such a "high" adverbial should be situated in a prominent position anyway. Soh's generalization does not apply to nonreason $w h$-adjuncts. When there is a potential quantifier barrier, the temporal adverbials shenmeshihou 'when' and jidian 'what time' show the opposite distribution to the reason adverbial: the temporal adverbials have to stay in situ following the quantifier, and fronting to a higher position would generate infelicitous sentences, as in Examples (10-11). I attribute this mismatch to the fact that reason adverbials are always located in a "high" position, yet other adjuncts such as temporal adverbials are generated in a lower position. Examples (12-13), which involve locative adverbials zai nali 'at where' and zai najia canting 'at which restaurant', show that locative $w h$-adverbials also have to stay in situ, instead of rising to a position preceding the quantifier. The same observation applies to source adverbials and manner adverbials in Examples (14-15) as well.
a. Zhangsan changchang shenmeshihou he jiu? Zhangsan often when drink alcohol 'When does Zhangsan often drink alcohol?'
b. * Zhangsan shenmeshihou changchang he jiu ${ }^{6}$ Zhangsan when often drink alcohol
a. Zhangsan changchang jidian dao?
Zhangsan often what.time arrive
'What time does Zhangsan often arrive?'

(11)

\footnotetext{
6 This sentence itself is not ungrammatical, but it fails to convey the intended interpretation as in Example (10a). Example (10b) actually interrogates the time period during which Zhangsan drinks alcohol frequently. The expected answer for Example (10a) could be "after dinner", whereas that for Example (10b) could be "while he was on the dole". The contrast between Examples (10a) and (10b) would not be clear if the action is scolding (as in Example [7]). It is the same for Examples (12) and (13). Of course, the native speaker's judgment might not be unanimous: an anonymous reviewer does not share the same intuition about the implied meaning in Example (10b), and their judgment on Example (11b/12b) is grammatical.
} 

b. * Zhangsan jidian
changchang dao?
Zhangsan

(12)

$\begin{array}{lllll}\text { a. Zhangsan changchang zai nali he jiu? } \\ \text { Zhangsan often } & \text { at where } & \text { drink alcohol }\end{array}$

'Where does Zhangsan often drink alcohol?'
b. * Zhangsan zai nali changchang he jiu?
Zhangsan at where often drink alcohol

(13) a. Zhangsan changchang zai na-jia canting chi fan?

Zhangsan often at which-CL restaurant have meal

'Where does Zhangsan often have meal?'

$\begin{array}{rllllll}\text { b. * Zhangsan } & \text { zai na-jia } & \text { canting changchang } & \text { chi fan? } \\ \text { Zhangsan } & \text { at } & \text { which-CL } & \text { restaurant } & \text { often } & \text { have meal }\end{array}$

(14) a. Zhangsan changchang cong nali jie shu?

Zhangsan often from where borrow book

'From where does Zhangsan often borrow books?'

b. * Zhangsan cong nali changchang jie shu?

Zhangsan from where often borrow book

(15) a. Zhangsan changchang zenme qu xuexiao?

Zhangsan often how go.to school

'How does Zhangsan go to school?'

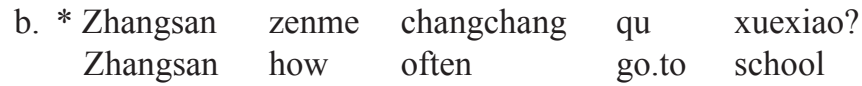

Similarly, when a temporal, locative, source, or manner $w$ h-adverbial is preceded by an "even"-focus, as in Examples (16a/17a/18a/19a), it has to remain in situ; otherwise, ungrammaticality results, as seen in Examples (16b/17b/18b/19b).
a. Lian Zhangsan dou jidian dao? even Zhangsan all what.time arrive 'What time does even Zhangsan arrive?'
b. * Jidian lian Zhangsan dou dao? ${ }^{7}$ what.time even Zhangsan all arrive
a. Lian Zhangsan dou zai na-jia canting chi fan? even Zhangsan all at which-CL restaurant have meal 'At which restaurant does even Zhangsan have meal?'

7 Again, Example (16b) is not ungrammatical, but it fails to convey both meanings of Example (16a). Example (16a) can show two scenarios, and Zhangsan is an early bird and a latecomer in each scenario, respectively. Accordingly, the interrogative time point is when even the early bird/latecomer Zhangsan arrives late/early. However, Example (16b) only implies that Zhangsan is a latecomer, and it questions the time point when even the latecomer Zhangsan arrives; Example (16b) cannot show the early bird scenario as in Example (16a). Note that according to an anonymous reviewer, Examples (16a) and (17a) are infelicitous. 
b. * Zai na-jia canting lian Zhangsan dou chi fan?

(18) a. Lian Zhangsan dou cong nali jie shu? even Zhangsan all from where borrow book 'From where does even Zhangsan borrow books?'

b. * Cong nali lian Zhangsan dou jie shu? from where even Zhangsan all borrow book

(19) a. Lian Zhangsan dou zenme qu xuexiao? even Zhangsan all how go.to school 'How does even Zhangsan go to school?'
b. * Zenme lian Zhangsan dou qu xuexiao? how even Zhangsan all go.to school

Therefore, quantificational or focus phrases do not impose any intervening effect on reason-adverbials or other wh-adjuncts. My conclusion is that neither quantificational nor focus phrases display the Intervention Effect on $w h$-adverbials, parallel to the fact concerning $w h$-nominals.

Interestingly, negation does display the Intervention Effect on temporal wh-adverbials, which is unexpected, because negation does not block the LF movement of nominal wh-phrases. If the ungrammaticality of Examples (20a/21a) is due to the distribution constraint (for instance, as a "high" adverbial, a reason $w h$-prepositional phrase $[\mathrm{PP}]$ must occur preceding the negation), the position of the temporal adverbial in Examples (20a/21a) should be acceptable, as a temporal adverbial does not need to be situated in a high position. However, Examples (20a/21a) are ungrammatical, and the temporal adverbial has to occupy a position preceding the negator, as in Examples (20b/21b); so, there must be a reason other than the distribution constraint, i.e., the Intervention Effect, of negation.
a. * Zhangsan bu shenmeshihou gongzuo? Zhangsan not when work
b. Zhangsan shenmeshihou bu gongzuo? Zhangsan when not work
'When does Zhangsan not work?'
a. * Zhangsan bu jidian gongzuo?
Zhangsan not what.time work
b. Zhangsan jidian bu gongzuo?
Zhangsan what.time not work
'What time does Zhangsan not work?'

Contrary to temporal $w h$-adverbials, locative $w h$-adverbials are not subject to the blocking effect triggered by intervening negation. As can be seen from Examples (22a/23a), the negator between locative wh-adverbials zai nali and zai na-jia 
canting and their Q-operators does not block the Q-binding, so wh-adverbials do not have to rise to a position c-commanding the negator. Moreover, if the whadverbials do move to a higher position across negation, as in Examples (22b/23b), although ungrammaticality does not arise, the original interpretation from Examples (22a/23a) might be changed. The same observation applies to source adverbials and manner adverbials, in Examples (24-25). Note that Example (25b) is a strong piece of evidence supporting the lack of any intervening effect on nontemporal $w h$-adverbials. Locative and source $w h$-adverbials have the option to stay in situ or move, but manner wh-adverbials have to stay in situ and cannot move across negation. If a manner adverbial "how" moved across the negator, although ungrammaticality would not result, the sentence would fail to convey the intended interpretation in Example (25a) and adopt the meaning 'reason-why', as seen in Example (25b).
a. Zhangsan bu zai nali he jiu?
Zhangsan not at where drink alcohol
'Where does Zhangsan not drink alcohol?'

b. Zhangsan zai nali bu he jiu?

Zhangsan at where not drink alcohol

(23) a. Zhangsan bu zai na-jia canting chi fan?

Zhangsan not at which-CL restaurant have meal

'At which restaurant does Zhangsan not have meal?'

b. Zhangsan zai na-jia canting bu chi fan?

Zhangsan at which-CL restaurant not have meal

(24) a. Zhangsan bu cong nali jie shu?

Zhangsan not from where borrow book

'From where does Zhangsan not borrow books?'

b. Zhangsan cong nali bu jie shu?

Zhangsan from where not borrow book

(25) a. Zhangsan bu zenme qu xuexiao?

Zhangsan not how go.to school

'How does Zhangsan not go to school?'

b. ? Zhangsan zenme bu qu xuexiao?

Zhangsan how not go.to school

'Why does Zhangsan not go to school?'

This observation on adverbial $w h$ - phrases $^{8}$ in modern Mandarin is different from that on nominal wh-phrases: focus phrases, but not negation or quantified

8 As pointed out by an anonymous reviewer, wh-adverbials here refer to canonical adverbials such as how or where, excluding why, as reason adverbials exhibit different properties from other adverbials. I will show that reason $w h$-adverbials are indeed subject to the Intervention Effect of focus in modern Mandarin. 
structures, impose the Intervention Effect on wh-nominals; negation, but not focus phrases or quantified structures, imposes the Intervention Effect on temporal whadverbials. The comparison is presented in Table 1.

Table 1 The Intervention Effect on wh-phrases in modern Mandarin

\begin{tabular}{|l|c|c|c|}
\hline \multirow{2}{*}{} & \multirow{2}{*}{$\boldsymbol{W h}$-nominals } & \multicolumn{2}{|c|}{$\boldsymbol{W h}$-adverbials } \\
\cline { 3 - 4 } & & Temporal & Other \\
\hline Focus & $\sqrt{ }$ & $*$ & $*$ \\
\hline Negation & $*$ & $\sqrt{ }$ & $*$ \\
\hline Quantifier & $*$ & $*$ & $*$ \\
\hline
\end{tabular}

As for subjects, although nominative-marked subjects (as opposed to topic-marked subjects) are interveners in Japanese and Korean, according to my observation, subjects in general do not display the blocking effect in modern Mandarin. As can be seen from Example (26a), when a which-phrase is c-commanded by a subject Zhangsan (as opposed to the topic xiaoshuo 'novel' in the left periphery), it may front to a higher position; but after fronting, this $w h$-phrase is still c-commanded by the subject. Moreover, it is even acceptable to have the whichphrase remaining in its postverbal base position, as in Example (26b). Similarly, the wh-phrase shenme yanse 'what color' is not affected by the c-commanding subject, so it may undergo short-distance movement to a higher position but still follow the subject, as in Example (27a), or stay in situ, as in Example (27b). Of course, if the wh-phrases do move to higher positions across the subjects, as in Examples $(26 \mathrm{c} / 27 \mathrm{c})$, the sentences do not become ungrammatical. The point is that when c-commanded by subjects, $w h$-phrases can move but definitely do not have to.
a. Xiaoshuo $o_{j}$, Zhangsan na-ben $n_{i}$ xiang kan $t_{i} t_{j}$ ?
b. Xiaoshuo ${ }_{\mathrm{i}}$, Zhangsan xiang kan na-ben $\mathrm{t}_{\mathrm{i}}$ ? novel Zhangsan want read which-CL

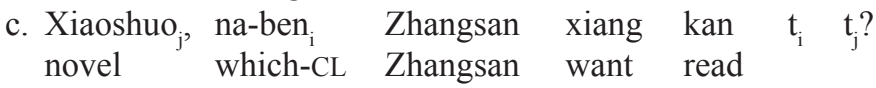 'As for novels, which does Zhangsan want to read?'
a. Lingdai, Zhangsan [shenme yanse-de $\left.\mathrm{t}_{\mathrm{j}}\right]_{\mathrm{i}}$ zui xihuan $\mathrm{t}_{\mathrm{i}}$ ? tie Zhangsan what color-SUB most like
b. Lingdai, Zhangsan zui xihuan [shenme yanse-de $\mathrm{t}_{\mathrm{i}}$ ? tie Zhangsan most like what color-SUB
c. Lingdai, $\left[\text { shenme yanse-de } t_{j}\right]_{i}$ Zhangsan zui xihuan $t_{i}$ ? tie what color-SUB Zhangsan most like 'As for ties, what color does Zhangsan like the most?' 
Tomioka (2007) points out the root-embedded asymmetry that the Intervention Effect is much weaker in embedded contexts. Tomioka proposes that the weakening is attributable to the fact that "non-topic subjects go to the ground portion more easily in embedded contexts than in root contexts", assuming that there is no topic-focus articulation in embedded sentences. Nevertheless, the observation that nonquantificational interveners lose the Intervention Effect in embedded contexts is not borne out in modern Mandarin. As shown in Example (28a), if a wh-phrase stays in its postverbal base position c-commanded by a nonquantificational determiner phrase (DP) "NP also", it cannot be bound by its operator preceding the nonquantificational DP, even if being embedded. To circumvent the blocking effect triggered by the nonquantificational DP, the wh-element has to move across the barrier, as in Example (28b).

$$
\begin{aligned}
& \text { a. ? Ni renwei Zhangsan ye kan-le na-ben shu? } \\
& \text { you think Zhangsan also read-ASP which-CL book } \\
& \text { b. Ni renwei [na-ben shu }]_{\mathrm{i}} \text { Zhangsan ye kan-le t } \mathrm{t}_{\mathrm{i}} \text { ? } \\
& \text { you think which-CL book Zhangsan also read-ASP } \\
& \text { 'Which book do you think that Zhangsan also read?' }
\end{aligned}
$$

Nonetheless, it is difficult to verify the generalization in LAC. First, owing to the short movement restriction on wh-elements in LAC, wh-movement into the complementizer phrase (CP) domain is restricted to a couple of topics anyway. Therefore, the lack of examples involving long distance wh-movement in the context of nominative-marked subjects is not necessarily due to the absence of the Intervention Effect triggered by subjects. Second, the weakening of the Intervention Effect in embedded clauses cannot be tested, in that biclausal examples are rare in corpora, apart from sentences with cleft constructions that do not simultaneously contain wh-elements.

In this paper, I investigate the Intervention Effect in LAC and modern Mandarin. In Section 2, I present the available syntactic, semantic, and pragmatic theories accounting for the Intervention Effect. In Sections 3, 4, and 5, I discuss the Intervention Effect of negation, focus, and quantifiers, respectively. Before drawing a conclusion in Section 7, I propound three obligatory requirements for the Intervention Effect to take place in Section 6.

\section{Literature review}

Wh-phrases fall into two groups, namely, nominals and adverbials (Tsai 1994, Tsai 1999). Different from nominal $w h$-phrases, adverbial $w h$-phrases cannot take scope across an island (Huang 1982; Tsai 1994, Tsai 1999). The Intervention Effect detects the $w h$-feature but not the $w h$-phrasal movement, in that the former leaves

9 According to an anonymous reviewer, Example (28b) sounds worse than Example (28a). 
the constraint on $w h$-quantification inside the clause, but the latter pied-pipes the constraint with the wh-phrase (Soh 2005).

As generalized by Pesetsky (2000), there are three kinds of movement relations in total: overt phrasal movement, covert phrasal movement, and feature movement. Both covert phrasal movement and feature movement are "invisible" movements, but only the latter is sensitive to the Intervention Effect; this means that $w h$-expressions affected by the Intervention Effect undergo feature movement. To answer the question of whether in-situ $w h$-items undergo covert movement or not, Cheng (2009) views the basic arguments for and against covert wh-movement, namely, the parallels between overt and covert movements, syntax-semantics arguments, as well as asymmetries concerning covert $w h$-movement. Cheng also considers three alternative accounts: movement of a particle/operator/feature, no movement, and disguised movement. Through discussion of the intervention effects explained by both syntactic and nonsyntactic treatments, along with multiple $w h$ questions, Cheng concludes that covert $w h$-movement is needed when accounting for in-situ $w h$-items. Although Pesetsky (1987) suggests that unselective binding takes care of the interpretation of D-linked in-situ expressions, Pesetsky (2000) argues that there is indeed movement.

With respect to the account for the Intervention Effect, there are, broadly speaking, three kinds of approaches: syntactic approaches, semantic approaches, and pragmatic approaches.

Beck and Kim (1997) observe that a wh-phrase must not be c-commanded by an NPI in Korean, which is related to the fact that a $w h$-phrase must not be c-commanded by negation or a negative quantifier. Both Korean and German are sensitive to the Minimal Negative Structure Constraint, which prohibits LF movement of $w$ h-in-situ across negation: if an LF trace $\beta$ is dominated by an NIB $^{10} \alpha$, then the binder of $\beta$ must also be dominated by $\alpha$ (Beck 1996a). In a multiple question whose ungrammaticality is caused by the occurrence of a negative quantifier, the interrogative operator is associated with the $\mathrm{C}^{0}$ position at (transparent) LF. In order to be interpreted as an interrogative wh-phrase, wh has to be interpreted outside the scope of the operator, so it has to end up in a position structurally more prominent than $\mathrm{C}^{0}$, but it leaves a trace (which only exists at LF) in the scope of negation. That is to say, there is covert movement from the medial domain up to $\mathrm{C}$. The relation between $w h$ and its LF trace is hence blocked by negation, which means that there is a restriction on the binding of LF traces. The foundation of Beck and Kim's theory is the postulation of a close correlation between c-command relations at the S-structure and the quantifier scope at LF. The S-structure-c-command relation is significant for the relative scope of quantifier phrases. Additionally, LF $w h$-movement is assumed to always

10 As defined by Beck and Kim (1997), "t[T] he first node that dominates a negative quantifier, its restriction, and its nuclear scope is a Negation-Induced Barrier (NIB)." 
create an LF trace in Korean and German. The Intervention Effect created by an intervening quantifier phrase (QP) that blocks the LF movement of an in-situ wh is sketched in Example (29).

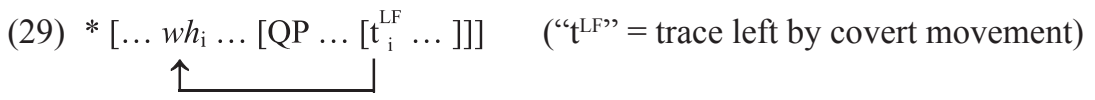

There are limitations on this LF-movement. Pesetsky (2000) points out that some in-situ wh-items in English do not have the Intervention Effect, but they undergo LF movement. Moreover, the different behaviors of quantifiers and focus constructions, as well as the canceling/weakening effect in embedded contexts proposed by Tomioka (2007), cannot be explained (Yang 2012).

Although Beck (1996b) states that Example (30) may not be a universal constraint, as English LF wh-movement does not observe it, Pesetsky (2000) suggests that the Intervention Effect is universally observed when Example (30) is regarded as a constraint on the wh-feature but not on wh-phrasal movement. The universal characterization of the Intervention Effect is in Example (31).

$$
*\left[\ldots \mathrm{X}_{\mathrm{i}} \ldots\left[\mathrm{Q} \ldots\left[\ldots \mathrm{t}_{\mathrm{i}}^{\mathrm{LF}} \ldots\right]\right]\right]
$$

(31) A semantic restriction on a quantifier (including wh) may not be separated from that quantifier by a scope-bearing element.

(Pesetsky 2000: 67)

The syntactic analysis of Pesetsky (2000) discusses the Intervention Effect in English and distinguishes two types of covert movement, i.e., covert phrasal movement and feature movement. Within the Minimalist Programme, feature movement is allowed at LF and is sensitive to the Intervention Effect. Contrary to feature movement, phrasal movement is not sensitive to the Intervention Effect. Wh-phrases, such as "what" and "who", can undergo covert phrasal movement, yet "which" cannot (Beck 2006). Wh-phrases that are insensitive to interveners move covertly past the interveners. D-linked wh-phrases do not have to move. Pesetsky's (2000) analysis accounts for the observation that which-phrases in (at least one dialect of) modern Mandarin show an intervening effect, but non-whichphrases do not:
a. \% Zhiyou Lili kan-le shenme? only Lili read-ASP what
b. ?* Zhiyou Lili kan-le na-ben shu? only Lili read-ASP which-CL book
c. Na-ben shu zhiyou Lili kan-le? which-CL book only Lili read-ASP 'Which book did only Lili read?' (Beck 2006: 27)

Pesetsky's (2000) theory based on the Separation Principle fails to account for the quantifier/focus distinction and the canceling/weakening effect in an embedded 
context either, parallel to the LF-movement theory. Furthermore, the Separation Principle approach cannot explain the disappearance of the Intervention Effect when focus constructions function as verb phrase (VP) adverbials in Mandarin (Yang 2012).

Extending Pesetsky's feature movement analysis to cover NPI-licensing, Guerzoni (2006) indicates that one type of LF operation, namely, quantifier raising, involves phrasal movement, yet the other type, i.e., wh-movement at LF, involves feature movement. Since there is a correlation of general intervention effects and a lack of superiority effects that wh-phrases move phrasally, covert phrasal movement must be unavailable in languages displaying intervention effects for wh-in-situ (Beck 2006).

Kim $(2002 b, 2005,2006)$ analyzes the blocking effect on LF (covert) dependency of wh-in-situ as a function variable bound by a Q-operator and proposes that it is a focus phrase that induces an Intervention Effect in modern Mandarin, instead of negation or quantifiers in general. A core set of intervention effects, viz., focus effect, has been extracted. Since both in-situ wh-constituents and focus constructions indicate a set of alternatives, they both entail a focus semantic value. Focus Intervention Effect occurs when an intervening focus operator (F-Op) assigns a value to an in-situ $w h$-item and checks off its uninterpretable focus feature. Since the valuation and checking do not involve movement, the focus effect does not need to resort to any movement mechanism. Additionally, there is a repair strategy to circumvent the Intervention Effect in modern Mandarin by means of raising in-situ $w h$-items to a position preceding the focus-induced barrier. Kim (2002a) reviews two intervention constraints, namely, Minimal Quantified Structure Constraint on LF movement of wh-in-situ (Beck 1996a) and Immediate Scope Constraint (Linebarger 1987), both of which postulate that LF dependency cannot cross a quantificational barrier. Kim (2002a) points out that both analyses face the overgeneralization problem. She proposes the Focus Intervention Effect, i.e., in a focus-sensitive licensing construction, an independent focus phrase cannot intervene between the licensor and the licensee. The licensing relationships of Q-operator and negator (NEG) (as focus-sensitive operators) are interrupted by another element with the same feature $[+\mathrm{Foc}]$, which can be considered as a case of the "Defective Intervention Effect" (Chomsky 2000, Chomsky 2001) in the sense that a focus-sensitive probe cannot AGREE with its goal carrying the same feature $[+\mathrm{Foc}]$ :

$$
\begin{aligned}
& *\left[_{\mathrm{CP}} \mathrm{Q}_{\mathrm{i}}\left[\operatorname{FocP}_{[+F o c]}\left[\ldots \mathrm{wh}_{\mathrm{i}[+F o c]} \ldots\right]\right]\right] \\
& *\left[\mathrm{NEG}\left[\mathrm{FocP}_{[+F o c]}\left[\ldots \mathrm{NPI}_{[+F o c]} \ldots\right]\right]\right]
\end{aligned}
$$

The semantic account proposed by Beck (2006) describes the Intervention Effect as the fact that a linguistic structure is ungrammatical if a focus-sensitive operator intervenes between an LF-in-situ $w h$ and the complementizer that 
interprets it. Beck (2006) assumes that a wh-phrase has a focus-sensitive value, rather than ordinary semantic value. Wh-questions are interpreted by the identical mechanism with focus, but unlike focus, wh-phrases only introduce alternatives and make no ordinary semantic contribution. The ordinary semantics of whphrases is undefined, but wh-phrases appear in expressions with well-defined ordinary semantic value. It is the question operator that rescues the structure from undefinedness. When a question contains a focus whose contribution is evaluated within the scope of the Q operator, as $\left[\mathrm{Q} \ldots\left[\mathrm{Op}\left[{ }_{\varphi} \ldots \mathrm{XP}_{\mathrm{F}} \ldots w h \ldots\right]\right]\right.$, the structure becomes unacceptable. The ordinary semantics of $\varphi$ is undefined, in that the $w h$ phrase has no ordinary semantics. Since the focus semantic value is reset to the ordinary semantic value, the sister of the Q-operator does not have either welldefined ordinary or well-defined focus semantic value, so the Q-operator cannot save the structure from undefinedness. Consequently, a wh-phrase requires a question operator $\mathrm{C}$ that must be the first focus-sensitive operator c-commanding the wh-phrase. A wh-phrase not c-commanded by a coindexed Q operator would be uninterpretable, as the expression cannot receive an ordinary interpretation. Other focus-sensitive operators perform on both the ordinary and focus-semantic values, so they would generate an uninterpretable structure if they apply to a wh-phrase without ordinary semantic value. As a consequence, the Intervention Effect occurs when other focus-sensitive operators come upon before C. The crucial element of this account is that both focus and wh are interpreted through the mechanism of distinguished variables; unlike focus, wh is evaluated by the question operator. To circumvent the Intervention Effect, wh must be scrambled across the focus-sensitive intervener to get its associated question operator.

In terms of the potential challenges for this approach based on focus intervention effects, the puzzles concerning embedded contexts and VP focus adverbials still exist, and additionally, this approach needs to address the contrast between the $w h_{1}$-in-situ in Example (35a) and the non- $w h_{1}$-in-situ in Example (35b) in English (Yang 2012).

(35) a. ?? Which boy did only Mary introduce which girl to

b. Which girl did only Mary introduce (Yang 2012: 54) to which boy? $\left(w h_{1}\right.$-in-situ) (non- $w h_{1}$-in-situ)

The pragmatic approach of Tomioka's (2007) derives the Intervention Effect from the notion of information structure. In a $w h$-question, the $w h$-word acts as the focus, and the remaining part is "discourse-old" (Prince 1981) or GIVEN (Schwarzschild 1999). A sentence can be divided into a focus and a ground, and a ground can be further divided into a link and a tail. It is difficult to classify interveners into one natural group, but all interveners share one property in common, namely, they cannot be topic-marked and hence are called anti-topic items (ATIs). An ATI belongs to a tail, but the pre-wh position is not suitable for a ground, so the mismatch between the information structure and its grammatical realization produces the Intervention Effect. Even if an ATI can be the ground part of a 
sentence, it cannot be the link and has to stay in the tail portion of the ground. The ability of scrambling to void the Intervention Effect is realized through placement of an ATI in the tail part of the sentence. The effect of scrambling lies in the fact that the scrambling of a $w h$ across an ATI generates a prosodic structure, so that the ATI is confined within the prosodically reduced part and becomes a part of the tail. That is to say, the circumvention of the Intervention Effect is also derived from information structural properties. However, as suggested by Cheng (2009), ATIs may in fact be focus items or they may have focus-sensitive operators, hence being connected to Beck's (2006) core case and Guerzoni's (2006) feature movement analysis.

According to Tomioka's (2007) pragmatic approach, nonquantificational DPs display the Intervention Effect in Japanese and Korean. This observation coincides with the data from modern Mandarin (36).
a. ? Lili ye kan-le na-ben shu?
Lili also read-ASP which-CL book
b. Na-ben shu Lili ye kan-le?
which-CL book Lili also read-ASP
'Which book did Lili, too, read?'
(Kim 2002b: 626)

Tomioka's (2007) theory based on the antitopicality effect, according to Yang (2012), solves the embedding problem, but it still needs to explain the contrast between the $w h_{1}$-in-situ Example (35a) and the non-wh-in-situ Example (35b) in English, as well as the reason why wh-adverbs like weishenme 'why' and zenme 'how' still encounter the Intervention Effect even if being embedded.

Noh (2011) proposes another pragmatic account, which is a cognitive account focusing on "NP-only" within the relevance-theoretic framework. In a scrambled sentence in Korean (Example [37b]), Minswu-man 'Minswu-only' is interpreted as old information, while only the wh-word is interpreted as a focus, because the $w h$ word has the priority in the hierarchy of all potential foci. Providing both Minswuman and the wh-word are interpreted as foci, the Intervention Effect would arise. As for the reason why Example (37b) is preferred to Example (37a), it may be explained by the relevance theory. The hearer follows the relevance-theoretic comprehension strategy: start deriving cognitive effects in order of accessibility; and stop when the expected level of relevance is achieved. Example (37a) makes the hearer interpret Minswu-man 'Minswu-only' as a focus first and then reanalyze it as a presupposition; so Example (37a) requires more processing effort but does not produce additional cognitive effect. Similarly, I assume that the reason why Example (28a) may not sound ungrammatical to some native speakers of Mandarin could be accounted for by this cognitive approach that "Zhangsan also" is treated as part of old information, but not a focus.
a. * Minswu-man
mues-ul
po-ass-ni?
Minswu-only
what-ACC
see-PST-Q 


$\begin{array}{lll}\text { b. Mues-ul Minswu-man } & \text { po-ass-ni? } \\ \text { what-ACC Minswu-only } & \text { see-PST-Q } \\ \text { 'What did only Minswu see?' } & \end{array}$

(Noh 2011: 180)

There is another semantic account addressing quantifier-induced intervention effects in Mandarin why-questions, proposed by Jin (2019). In line with Ko (2005) and Tomioka (2007) that some quantifiers can be topics while others must stay in their scope position, Jin suggests that the ability of quantifiers to impose the Intervention Effect relies on their monotonicity and the possibility for them to be interpreted as topics. Due to the fact that Mandarin why directly merges at a high scope position above a propositional argument, why-questions in Mandarin are semantically idiosyncratic. Together with the semantic idiosyncrasies, the theory of topicality attributes the Intervention Effect to interpretation failure.

Yang $(2008,2012,2015)$ summarizes a weak/strong divide with regard to the intervention paradigm in Mandarin: when quantifiers act as interveners, the Intervention Effect is weak in a sense that only $w h$-adverbs, but not $w h$-arguments, are sensitive to it; when the interveners are associated with focus, the Intervention Effect is strong, and consequently, both $w h$-adverbs and $w h$-arguments are subject to it. Table 2 demonstrates the observation. To account for the weak/strong distinction, Yang suggests that the weak/quantifier-induced Intervention Effect is regulated by a locality condition and modeled with the minimality effect, in line with Rizzi's (2004) Revised Relativized Minimality, whereas the strong/focus-induced Intervention Effect is derived from the traditional "one-slot-per-Comp" notion. The weak/quantifier-induced Intervention Effect depends on feature movement, because it appears when the feature movement of an interpretable feature $\left[i \mathrm{~F}_{1}\right]$ of $\mathrm{Y}$ is blocked by an intervening $\mathrm{Z}$ of the same feature (as in Example [38]). Thus, the disparity between the minimality approach and Pesetsky's (2000) approach is that the former relies on the blocking of movement, but the latter relies on the Separation Principle. When it comes to explaining wh-arguments in Mandarin, Pesetsky's feature movement account would predict that they undergo covert phrasal movement in order to avoid the separation effect, yet Yang's minimality account permits $w h$-arguments to stay in situ at LF. When accounting for strong/ focus-induced Intervention Effect, Yang agrees with Kim (2005) and Beck (2006) that the focus Intervention Effect is triggered by focus conflict, but he attributes the strong/focus-induced Intervention Effect to the competition between an F-Op and an in-situ $w h$-item for a single slot, instead of the checking/licensing condition of in-situ $w h$-items. When a Q-operator (Q-Op) is base-generated at C-head and binds the in-situ $w h$-argument in Mandarin, this $w h$-argument adopts a nonmovement mechanism. The competition happens in focus phrase (FocP) within the $\mathrm{CP}$ domain, as shown in Example (39). Categorizing the Intervention Effect into the minimality effect and the competition effect successfully explains the root-embedded contrast, nonsubject interveners, as well as the Specifier (Spec)-head difference. 
Table 2 The weak/strong divide

\begin{tabular}{|l|c|c|}
\hline & Wh-argument & $\boldsymbol{W h}$-adverb \\
\hline Weak/quantifier-induced Intervention Effect & Okay & $*$ \\
\hline Strong/focus-induced Intervention Effect & $*$ & $*$ \\
\hline
\end{tabular}

Note: $*=$ sensitive; okay $=$ insensitive.

(Yang 2012: 58)

(38) Minimality effect

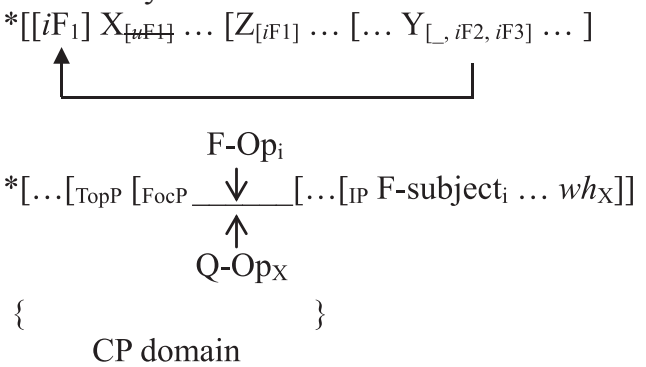

Nevertheless, Yang's theory is not adopted in this paper. First, according to Li and Cheung (2015), what triggers the focus-induced Intervention Effect is not competition between the focus and question operators. Second, as pointed out by Yang (2012) himself, the strong/focus-induced Intervention Effect cannot be fully remedied by the embedded context, which needs to be accounted for. Third, empirical data show that the majority of $w h$-adverbials do not display the focusinduced Intervention Effect in Mandarin, different from what is indicated by this theory.

\section{The intervention effect of negation}

Negation displays the Intervention Effect in LAC. Two types of $w h$-items are subject to the Intervention Effect triggered by negation: (1) wh-arguments and adverbials that are supposed to move to a focus position below negation; and (2) wh-phrases that can, but do not have to, stay in situ.

\subsection{Wh-constituents in the low focus position}

Non-D-linked $w h$-complements within the $v \mathrm{P}$ and $w h$-adverbials (base-generated either between negation and $\nu \mathrm{P}$ or postverbally) undergo obligatory movement. Owing to their focal nature, preposed $w h$-phrases should target a focus position below negation (termed as the "low focus position"). However, these wh-arguments and adverbials are subject to the Intervention Effect triggered by negation. As a consequence, whenever there is a negator, a $w h$-constituent must rise to a higher focus position (termed as the "high focus position") c-commanding negation so as to realize Q-binding. 


\subsubsection{Wh-arguments}

$W h$-adverbials may front overtly to one of the preverbal positions in the medial domain triggered by obligatory wh-fronting of LAC, and if they are non-D-linked, their landing sites are focused. I suggest that nonreason whadverbials rise to the Low focus position between negation and $v \mathrm{P}$, as shown in the template in Example (40). This template, for the first time, summarizes a complete hierarchy for preposed and in-situ $w h$ - and non-wh-elements in LAC, covering both the left periphery and the sentence-internal area. This hierarchy demonstrates the relative orders between the base positions and landing sites of wh-items, as well as between fronting positions and medial elements. This hierarchy also reveals the locations of key elements, such as negation and an adverb 獨 $d u$ 'alone',11 which can diagnose the position where negation is generated.

(40) Clausal positions for $w h$ - and non-wh-fronting:

External topic position $>$ Subject $>$ Internal topic position $>$ High focus position $>$ High $w h$ base position $>$ Modal adverbs $>$ Aspectual/temporal adverbs $>$ Focus position $>$ 獨 $d u>$ Negation $>$ Low focus position $>$ Low $w h$ base position $>$ Root modal verbs $>v \mathrm{P}$

The reason why I claim that there are multiple focus positions, viz., the High focus position, the Focus position, and the Low focus position, lies in the coexistence of more than one fronting element (Examples [41a-b]) and their relative ordering with negation or the key diagnostic adverb (Examples [41c-f]). See Wang (2016) for more detailed discussions and examples.
a. 此言 何 謂?

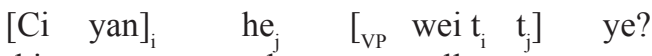
this sentence what call DECL
'How (do we) understand this sentence?' (Lit. 'What [do we] call this sentence?')
(Mengzi•Tengwengongshang)

11 The adverb 獨 $d u$ 'alone' always immediately precedes negation, and no element can intervene between $d u$ and the following negative (Example [i]), so it is treated as a key diagnostic element. If a $w h$-element precedes or follows $d u$, then this $w h$ must precede or follow the position of negation accordingly. Therefore, $d u$ is a crucial diagnostic element to decide the relative order between $w h$-phrases and negation, even without the presence of negators (Wang 2015).

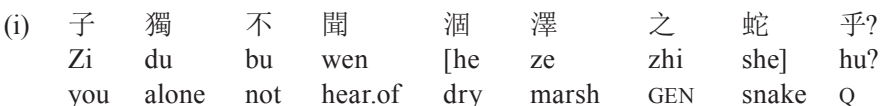
'Have you alone not heard of (the parable about) snakes in a dry marsh?' (Hanfeizi $\bullet$ Shuolin) 


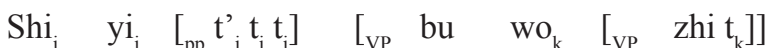

this for not me understand

'(People) for this do not understand me'

(Daodejing)

c. 吾 斯之 未 能 信

$\mathrm{Wu} \quad \mathrm{si}_{\mathrm{i}} \quad$ zhi wei neng $\left[_{\mathrm{VP}} \quad \mathrm{xin}_{\mathrm{i}}\right]$

I this ZHI not.yet can be.confident.in

'I have not been able to be confident in this'

(Analects ${ }^{\bullet}$ Gongyechang)

d. 未能行

Wei zhi ${ }_{i}$ neng $\left[{ }_{V P}\right.$ xing $\left.\mathrm{t}_{\mathrm{i}}\right]$

not.yet 3.OBJ can execute

'before (he) can execute it'

(Analects•Gongyechang)

e. 吾 何 為獨 不 然?

$\mathrm{Wu}$ he ${ }_{i} \quad$ wei $_{j}\left[\mathrm{pp}_{\mathrm{p}} \mathrm{t}_{\mathrm{i}} \mathrm{t}_{\mathrm{j}} \mathrm{t}_{\mathrm{i}}\right]$ du bu ran?

I what for alone not correct

'For what am I alone not correct?'

(Mengzi $\bullet$ Gongsunchouxia)

f. 先生 獨 何 以 ${ }^{2}$ 說 吾 君 乎?

Xiansheng du he $\mathrm{yi}_{\mathrm{j}} \quad\left[\mathrm{PP}_{\mathrm{PP}} \mathrm{t}_{\mathrm{i}} \mathrm{t}_{\mathrm{j}} \mathrm{t}_{\mathrm{i}}\right]$ [vp $_{\mathrm{vP}}$ yue wu jun $]$ hu? $\operatorname{sir}($ you $)$ alone what with please my lord $\mathrm{Q}$

'How did you alone please my lord?'

(Zhuangzi $\bullet$ Xuwugui)

Before discussing non-D-linked wh-complements, it should be mentioned that D-linked which-phrases and non-D-linked wh-phrases like "what" do not display such a difference in LAC. For instance, the LAC wh-phrase 何 he does not show "which" and "what"-phrase distinction (Example [42]).
a. 將 何 不 忘哉!
Jiang he $\mathrm{i}_{\mathrm{i}}$ bu $\left[_{\mathrm{VP}}\right.$ wang $\left.\mathrm{t}_{\mathrm{i}}\right]$ zai!
FUT what not forget EXCL
'What will (he) not forget!'
(Hanfeizi・Yulao)
b. 孰 不 可 忍 也!
$\mathrm{Shu}_{\mathrm{i}}$ bu ke $\left[\mathrm{vp}_{\mathrm{vp}}\right.$ ren $\left.\mathrm{t}_{\mathrm{i}}\right]$ ye!
which not can endure DECL
'Which cannot (he) endure!'
(Analects•Bayi)

12 In this paper, I treat the morpheme 以 $y i$ in the instrumental wh-YI as a preposition "with" heading an adjunct prepositional phrase, following the traditional analyses (Wang 2004 [1958], Wang 1981 [1962]; Zhou 1959; Peyraube 1996, Peyraube 1997; Guo 1998; Djamouri 2009, among many others). 
Parallel to nonreason $w h$-adverbials, non-D-linked $w h$-arguments may also front to the Low focus position. Recall the clausal positions for $w h$-fronting and medial elements (Example [40]), the aspecto-temporal adverb 將 jiang 'will'13 intervenes between the High focus position and the Low focus position. In Example (43), since the fronted wh-argument 何 he 'what' follows the aspecto-temporal adverb jiang, this preposed wh-nominal must have risen into the Low focus position intervening between negation and the $v \mathrm{P}$. The purpose of Example (43) is to show that without negation, non-D-linked $w h$-phrases (like $h e$ ) front to the Low focus position and stay in the Low focus position.

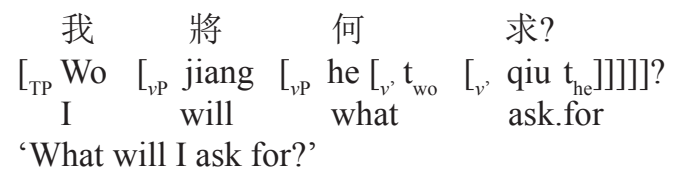

(Zuozhuan Xigong 28; Aldridge 2010: 11)

Example (43) does not involve negation, and we do not expect negation to make any difference based on data in modern Mandarin. Nevertheless, such a prediction is not borne out for LAC, in that if a negative element is present and c-commands an interrogative wh-phrase, the negator will block the LF dependency of the wh-constituent, due to the Intervention Effect (Beck 1996a; Beck and Kim 1997; Kim 2002b, Kim 2005, Kim 2006). The Intervention Effect of negation is not unexpected, as association with focus applies to negation, and NEG is a focus-sensitive operator that has undergone an association with focus. To be in a position where it may be interpreted semantically, the focused $w h$-DP has to adopt a repair strategy by fronting to a position across negation, until the blocking effect is circumvented. As a consequence, the surface landing position of a whconstituent is always above negation, corresponding to Aldridge's (2006, 2007, 2010) observation that $w h$-words never follow negators.

In order to justify the presence of the Intervention Effect of negation on nonD-linked nominal wh-phrases in the Low focus position, I refer to instances like the second clause in Example (44), where a wh-object 何 he lands in a position preceding negation. This bare $w h$-word 何 he is supposed to rise from its postverbal base position to a preverbal position. As a non-D-linked $w h$-DP, he is supposed to land in a focalized position; moreover, its VP-internal base position indicates that it should move to the Low focus position. However, when the wh-word he appears in the Low focus position, it is c-commanded by a negator 不 $b u$, which is an intervener blocking LF dependency of he; so he needs to move to a position over negation in order to be bound by a Q-operator. Since he is non-D-linked, this position cannot be the External/Internal topic position, but rather the High focus position, which is supposed to accommodate "high" adverbials exclusively.

13 See Meisterernst (2008) for the nature of 將 jiang as an aspecto-temporal adverb. 
That is to say, the preposing of he should have targeted the Low focus position, motivated by obligatory wh-fronting; however, due to a blocking negator, the whfronting now targets the High focus position, triggered by the Intervention Effect of negation. Therefore, I argue that when c-commanding a non-D-linked $w h$-DP that is supposed to land in the Low focus position, the Intervention Effect of negation applies to the wh-nominal and triggers its fronting to the High focus position. Consequently, in the two sentences of Example (44), he occupies distinct positions: it occurs in the High focus position in the latter clause, whereas it merely moves to the Low focus position in the former clause. Providing negatives is not a barrier for the interpretation (Q-binding) of wh-constituents; he in the second clause of Example (44) would end up in the Low focus position, analogous to its counterpart in the first sentence.

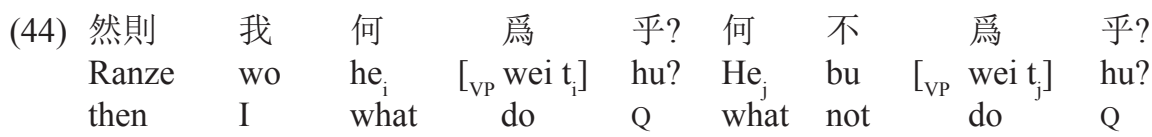
'Then what do I do? What (do I) not do?'

(Zhuangzi $\bullet$ Qiushui)

Examples (45a) and (45b) are cited here to reinforce the availability of a focused position below negation. 焉 yan 'where' in Example (45a) functions as the complement of the verb 適 shi 'go', and it rises from its postverbal base position to a preverbal position following the aspecto-temporal adverb 將 jiang. Since jiang intervenes between the High focus position and the Low focus position, the landing site of yan should be the Low focus position that is below negation. Example (45b) shows the preposing of a wh-adjunct from its preverbal base position to a higher position. The key diagnostic element 獨 $d u$ 'alone' indicates that the landing site of this manner wh-PP is below negation, as this adverb always immediately precedes negation, and no element can intervene between $d u$ and the following negative.

$$
\begin{aligned}
& \text { a. 夫子 將 焉適? } \\
& \text { Fuzi jiang yan } \left.{ }_{\mathrm{i}} \quad \text { V }_{\mathrm{VP}} \text { shi }_{\mathrm{i}}\right] \text { ? } \\
& \text { sir(you) FUT where go } \\
& \text { 'Where will you go?' } \\
& \text { (Lüshichunqiu } \bullet \text { Jidongji) } \\
& \text { Xiansheng du he } \left.\mathrm{yi}_{\mathrm{i}}\left[{ }_{\mathrm{PP}} \mathrm{t}^{\prime} \mathrm{t}_{\mathrm{j}} \mathrm{t}_{\mathrm{i}}\right]\right] \quad\left[\mathrm{VP}_{\mathrm{P}}\right. \text { yue wu jun] hu? } \\
& \operatorname{sir}(\mathrm{you}) \text { alone what with please my lord Q } \\
& \text { 'How did you alone please my lord?' } \\
& \text { (Zhuangzi } \bullet \text { Xuwugui) }
\end{aligned}
$$

Example (46) is a piece of evidence that rules out the possibility of passivization and proves that the $w h$-word $h e$ 'what' is a fronted object, instead of an internal argument moved to the left periphery. The wh-DP he should not be treated as moving to the subject position, in that he is below the aspecto-temporal adverb 將 
jiang 'will', which always follows the subject. This argumentation coincides with Aldridge's $(2006,2007,2010)$ generalization that the landing site of $w h$-fronting in LAC is always lower than T.

(46)

$\begin{array}{llll}\text { 將 何 不 } \quad \text { 忘 } & \text { 哉! } \\ \left.\text { Jiang he }{ }_{\mathrm{i}} \text { bu } \text { [VP }_{\mathrm{VP}} \text { wang } \mathrm{t}_{\mathrm{i}}\right] & \text { zai! } \\ \text { FUT what not forget } & \text { EXCL } \\ \text { 'What will (he) not forget!' } & \\ \text { (Hanfeizi・Yulao) } & \end{array}$

The tree diagram of the second question in Example (44) is presented in Example (47).

(47)

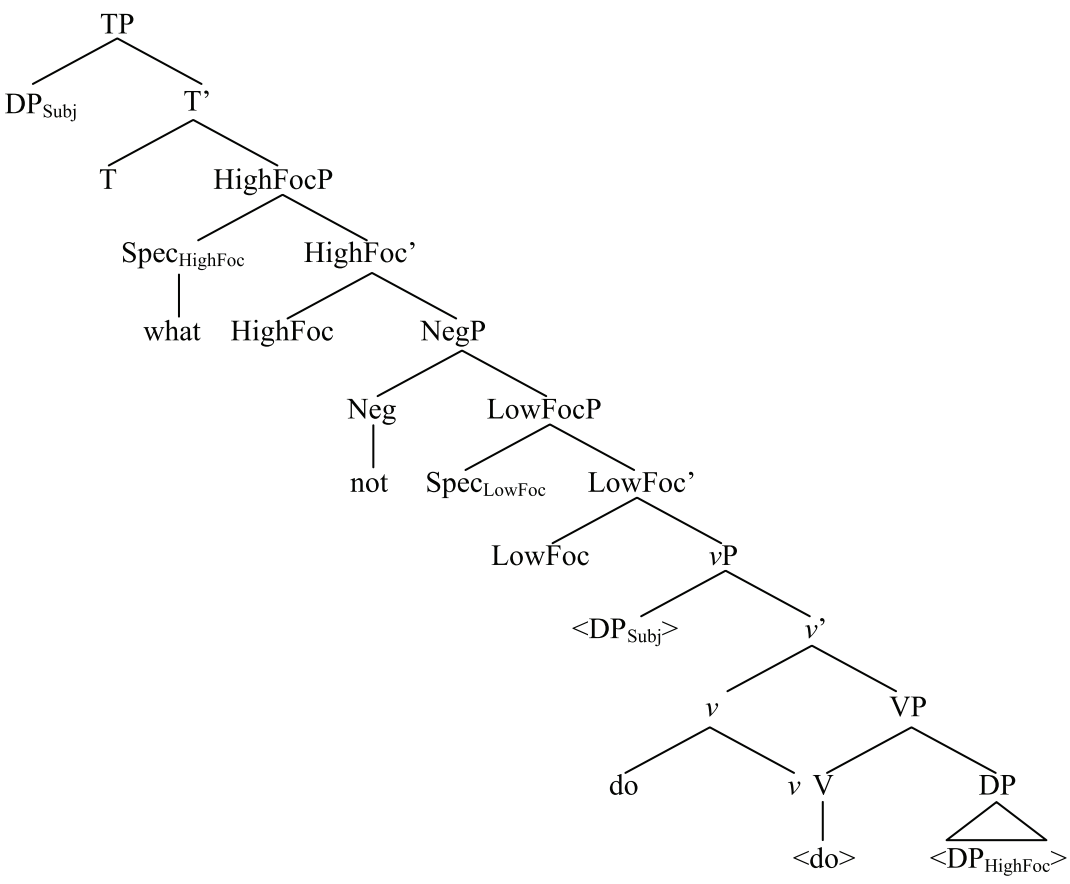

Apart from being simplex, $w h$-DPs intended to land in the Low focus position but undergone fronting to the High focus position could be complex as well, as shown in Example (48).

$\begin{array}{lllllc}\text { a. 宋 } & \text { 何 } & \text { 役 } & \text { 之 } & \text { 不 } & \text { 會, } \\ \text { Song } & {[\text { he }} & \text { yi }]_{\mathrm{i}} & \text { zhi } & \text { bu } & \left.{ }_{\mathrm{VP}} \text { hui } \mathrm{t}_{\mathrm{i}}\right] \\ \text { Song } & \text { what } & \text { battle } & \text { ZHI } & \text { not } & \text { enter } \\ \text { 而 } & \text { 何 } & \text { 盟 } & \text { 之 } & \text { 不 } & \text { 同? } \\ \text { er } & {[\text { he }} & \text { meng }]_{\mathrm{j}} & \text { zhi } & \text { bu } & \left.\text { [ }_{\mathrm{VP}} \text { tong } \mathrm{t}_{\mathrm{j}}\right] \text { ? } \\ \text { CONJ } & \text { what } & \text { alliance } & \text { ZHI } & \text { not } & \text { join }\end{array}$


'What battle does the State of Song not enter, and what alliance (does it) not join?'

(Zuozhuan•Zhaogong 25)

Guo zhi shougui, qi [he shi $]_{\mathrm{i}}$ bu [ $\left.\mathrm{Vp}_{\mathrm{p}} \mathrm{bu}_{\mathrm{i}}\right]$ ?

state GEN tortoiseshell MOD what thing not divine

'Speaking of the tortoiseshell of the state, what thing does it not divine?' (Zuozhuan•Zhaogong 5)

It is notable that the High focus position is supposed to allow "high" $w h$-adverbials exclusively, but the Intervention Effect of negation causes non-D-linked wh-DPs to move into this position as well, as illustrated by Examples (44) and (48).

\subsubsection{Wh-adverbials}

Adjunct adverbials are always above negators in the context of negation, ${ }^{14}$ and no examples of *Neg (VP) wh (VP) are ever attested. This observation is not surprising for reason $w h$-adverbials whose base position is already above negation. However, for a nonreason $w h$-adverbial base-generated postverbally or preverbally but below negation, it cannot be bound by a Q-operator, owing to the intervening negator that blocks LF movement of $w h$-in-situ to an operator position. Consequently, to be in a position where it can be interpreted semantically, this wh-adverbial must adopt a repair strategy by fronting to the High focus position that is not c-commanded by negation at S-structure. Note that analogous to the pre- or postverbal base position, the Low focus position cannot accommodate whadverbials either, because it is equally c-commanded by negation. Since adjunct adverbials could be base-generated in two positions, they may either move from the higher base position between negation and $v \mathrm{P}$ or from the postverbal base position to the High focus position.

Location, source, and instrument $w h$-adverbials are subject to the Intervention Effect of negation.

First, as illustrated earlier, locative adverbials are either base-generated preverbally (Examples [49a-b]) or postverbally (Example [49c]), and their whcomplements should move to a position between negation and $v$ P. In Examples $(49 \mathrm{a} / \mathrm{c})$, where negation is absent, the simplex wh-word 焉 yan 'where' and the complex $w h$-phrase 惡許 $w u x u$ 'what place' land in a position following the aspecto-temporal adverb 將 jiang that intervenes between the High focus position and the Low focus position, so the wh-adjuncts yan and wu $x u$ must land in the Low focus position below negation. However, in the context of negation, 安 an 'where'

14 This observation may be supported from a phonological point of view. The wh-word 何 he and the negator 不 $b u$ undergo a process of phonological reduction, generating a fusion form 盍 $h e$ $[h e+b u]$ 'why not'. Within this fusion form, the $w h$-adverbial of reason precedes the negator (Pulleyblank 1995; Feng 1996). 
in the second clause of Example (49b) and 何所 he suo 'what place' in Example (49d) move overtly from their base position between negation and $\nu \mathrm{P}$ to the High focus position across the negative. It can be seen that negation functions as a barrier for the Q-binding of $w h$-adverbials base-generated above $v \mathrm{P}$ and postverbally: they would have targeted the Low focus position if there was no Intervention Effect of negation. However, the Low focus position cannot accommodate the wh-PPs, as it is c-commanded by the negator $b u$, parallel to the base positions. So instead of rising to the Low focus position and still being c-commanded by the intervener, wh-elements target the High focus position c-commanding the negative intervener.
a. 將
焉
闢之?
Jiang $\operatorname{yan}_{\mathrm{i}}\left[{ }_{\mathrm{pp}} \mathrm{t}^{\prime} \mathrm{t}_{\mathrm{i}}\right] \quad \mathrm{b}$
zhi?
FUT where
avoid 3.OBJ

'Where will (I) avoid it?'

\section{(Zuozhuan Xigong 9)}

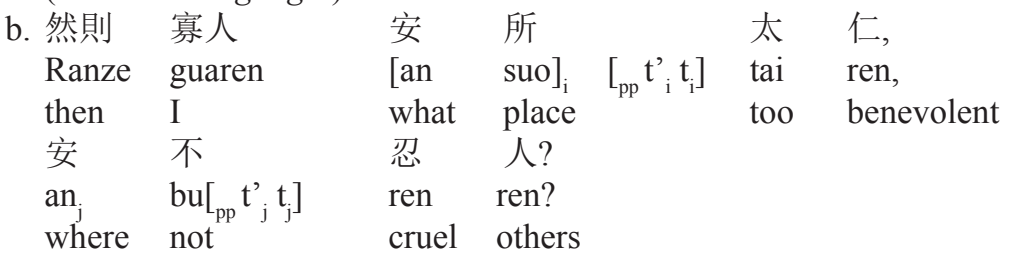

'Then (in) what place am I too benevolent, (and) where (am I) not cruel (to) others?'

(Hanfeizi $\bullet$ Neichushuoshang)

\begin{tabular}{|c|c|c|c|c|c|}
\hline “吾 & 將 & 惡 & 許 & 用 & 之?” \\
\hline $\mathrm{Wu}$ & jiang & [wu & $\mathrm{xu}]_{\mathrm{i}}$ & yong & zhi $\quad\left[{ }_{p p} t^{\prime}{ }_{i} t_{i}\right]$ ? \\
\hline I & FUT & what & place & use & 3.OBJ \\
\hline 曰: & “舟 & 用 & 之 & 水...” & \\
\hline Yue: & "Zhou & yong & zhi & shui..." & \\
\hline $\mathrm{s}$ & boat & use & 3. OBJ & water & \\
\hline
\end{tabular}

“"(In) what place will I use them?" (Mozi) said: 'Boats, (you) use them (on) the water..."”

(Mozi•Feile)

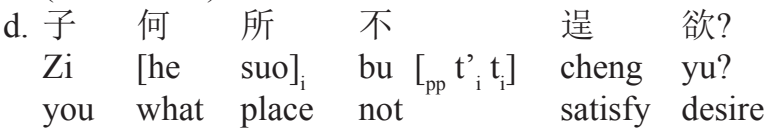

'(In) what place do you not satisfy desires?'

(Zuozhuan•Zhaogong 14)

Second, source PPs are base-generated preverbally (Example [50a]) or postverbally (Example [50b]), and their wh-complements should target a landing site between negation and $v$ P, i.e., the Low focus position. However, with the presence of negation, source PPs always appear in a position preceding the negator (Example [50c]). This fact also lends support to the proposal that the intervening negator blocks LF movement of a wh-element to an operator position, so the wh-element 
has to rise to a position c-commanding the barrier, which is the High focus position. The tree diagram of Example (50c) is in Example (50d).
a. 將
何
所
取?
Jiang $[$ he
suo $]_{i}\left[{ }_{P P} t^{\prime}{ }_{i} t_{i}\right.$
qu?
FUT what place
obtain
'(From) what place will (they) obtain (land)?'
(Zuozhuan $•$ Zhaogong 29)

b. 仲尼焉學?

Zhongni yan ${ }_{\mathrm{i}} \quad\left[\mathrm{V}_{\mathrm{VP}} \mathrm{xue}\right]\left[\mathrm{pp}_{\mathrm{pp}} \mathrm{t}_{\mathrm{i}} \mathrm{t}_{\mathrm{i}}\right]$ ?

Zhongni where study

'(From) where does Zhongni study?'

(Analects•Zizhang)
c. 夫子 焉 不
學?

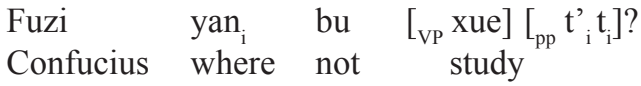
'(From) where does Confucius not study?'
(Analects•Zizhang)

d.

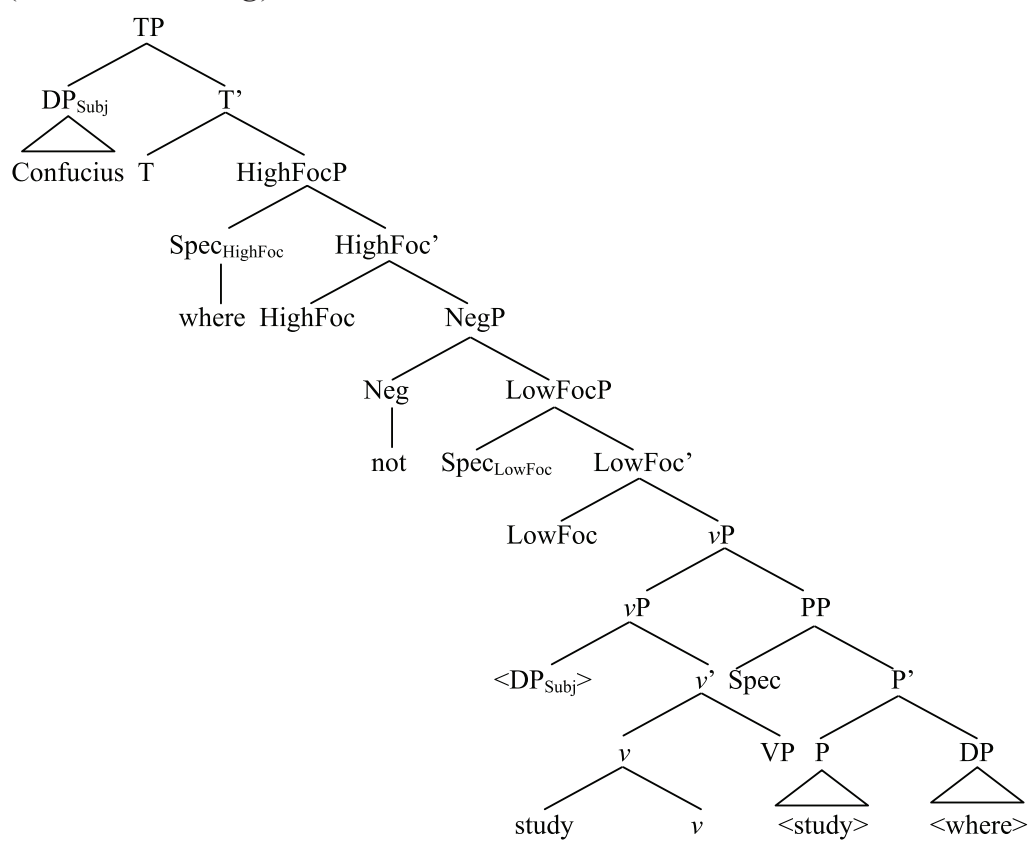

Third, wh-phrases functioning as adverbials of instrument are also subject to the Intervention Effect of negation. Adverbials of instrument headed by a preposition 以 $y i$ 'with' are base-generated lower than negation, because they follow the adverb 獨 $d u$, which always immediately precedes the negator 不 $b u$ (Example [51]). So, despite the absence of negation in instances involving instrumental PPs, the wh-complements are predicted to target the specifier node of the Low 
Focus projection below the negation phrase (NegP), triggered by obligatory $w h$-preposing, and the preposition 以 $y i$ 'with' should rise to the head of Low focus position.

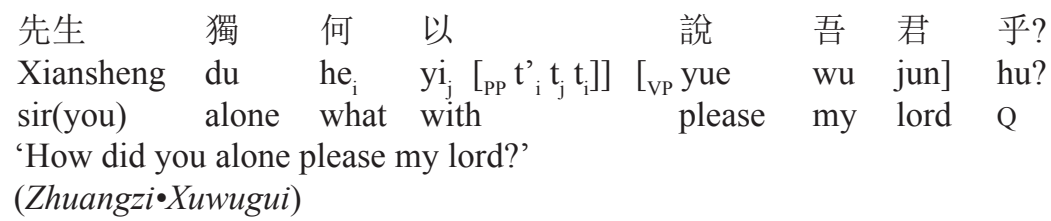

Nevertheless, the configuration of *Neg what $y i$ 'with' is never attested, ${ }^{15}$ which validates the Intervention Effect of negation. Providing a negative precedes an adverbial of instrument, this wh-yi adjunct has to move past negation in order to be bound by its Q-operator, because the negator blocks the Q-binding. There is no denying the fact that the prediction concerning movement of $w h$ along with $\mathrm{P}$ "with" is not borne out, and all what-P-Neg patterns involve adverbials of reason. This phenomenon is understandable: if a wh-P further moved to the High focus position preceding negation, which is expected to accommodate adverbials of reason exclusively, it would appear to be identical with wh-P "why" in the surface structure. As can be seen from Examples (49d) and (50c), those adverbials that can front to the High focus position do not adopt the wh-P pattern but are in the form of simplex or complex $w h$, so their fronting would not cause confusion between reason adverbials and nonreason adverbials raised to the High focus position; that is why the prediction concerning frontings of $w h$ and $y i$ to the High focus position is not borne out.

It could be argued that preposed wh-phrases, including both arguments and adverbials, always move to the same, higher position, regardless of being in an affirmative or negative environment. Nonetheless, the higher position, i.e., the High focus position, is supposed to allow "high" reason wh-adverbials exclusively, not other adverbials or wh-DPs. According to cross-linguistic evidence and data from modern Mandarin, adverbials indicating reason are located more prominently than other adverbials. Naturally, when a reason $w h$-adverbial takes the form of PP and the prepositional complement rises to a position preceding the preposition, this preposed $w h$ should be higher than a wh from a nonreason PP, because their base positions are uneven. In Example (52), there are two wh-PPs headed by different prepositions: the higher PP is an adverbial of reason, and the lower PP acts as an instrumental adverbial. As can be seen from Example (52), the reason PP is base-generated above the instrument PP, so after their complements move, the reason $w h$ is still above the instrument $w h$. That is to say, the reason $w h$-adverbial occupies the High focus position, whereas the nonreason $w h$-adverbial lands in the Low focus position. Nevertheless, due to the influence of the Intervention Effect,

15 It is not possible to find positive evidence for this claim, but there are no counterexamples to the generalization in the databases. 
non-D-linked DPs and nonreason adverbials have to move into the High focus position as well and share this position with reason adverbials. However, if $w h$ DPs and nonreason adverbials are not affected by the Intervention Effect, they only need to target the Low focus position. Therefore, wh-phrases do not move to the same position in different environments.

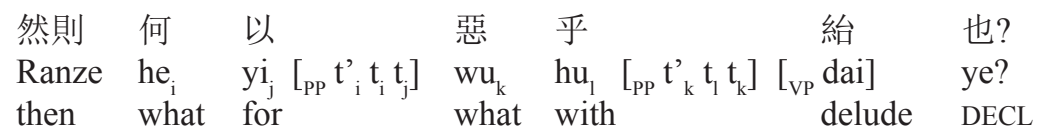

'Then what for and what with to delude?'

(Guliangzhuan $•$ Xigong 1)

\subsection{Wh-in-situ}

Manner adverbials may either be base-generated preverbally (Example [53a]) or postverbally and stay in situ (Example [53b]). Nevertheless, in the context of negation, the wh-adverbial of manner 奈何 nai he must appear in a position c-commanding the NIB, namely, the High focus position (Example [53c]).

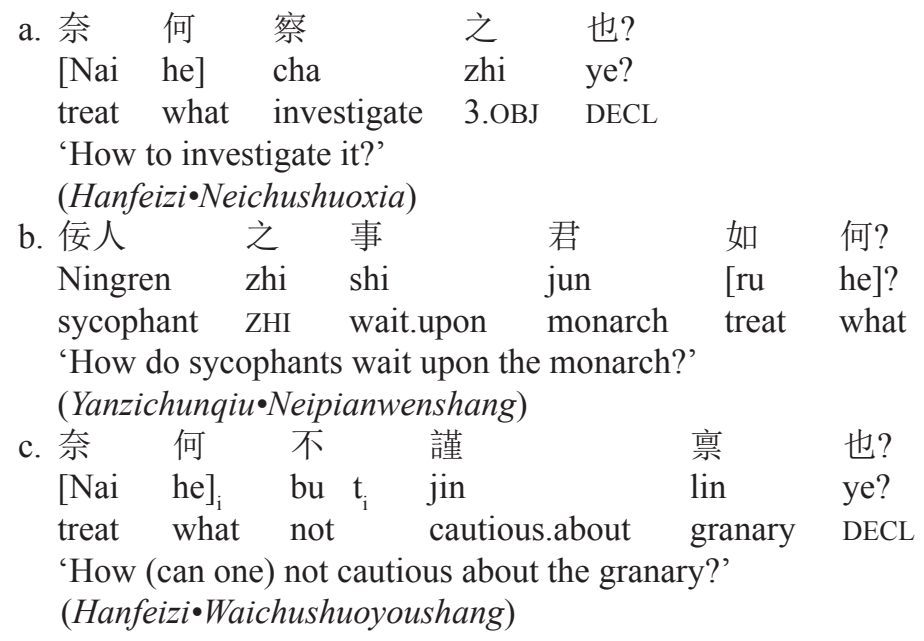

I assume that the base position of 奈何 nai he in Example (53c) is above the VP, because the same expression is base-generated preverbally in Example (53a), which is a canonical sentence without negation and hence no fronting. Of course, it is equally tenable that nai he could be base-generated in a postverbal position and this manner adverbial could move all the way from a postverbal position to the High focus position.

Now, we can conclude that the High focus position is expected to permit reason wh-adverbials exclusively, but due to the Intervention Effect of negation, the following four types of $w h$-phrases must rise to the High focus position too in the context of negation: (1) VP-internal wh-nominals that are expected to front to the Low focus position; (2) wh-adverbials base-generated between negation and 
the VP, which are expected to front to the Low focus position; (3) wh-adverbials base-generated postverbally, which are expected to front to the Low focus position; and (4) wh-adverbials base-generated postverbally, which are expected to stay in situ. In these situations, these wh-nominals and adverbials may also target the High focus position.

I follow Pesetsky's (2000) categorization of wh-phrases into overt phrasal movement, covert phrasal movement, and feature movement. However, I state that LAC does not permit covert phrasal movement; so, wh-phrases undergo either overt phrasal movement or feature movement. In the context of negation, an X-phrase (XP) $[+w h]$ first fronts to a position below the NIB, introduced by overt phrasal movement, and then the $[+w h]$ feature is interpreted by feature movement. All four types of wh-phrases mentioned above fall into this situation.

The distribution of interrogative $w h$-nominals and $w h$-adverbials with and without negation is demonstrated in Table 3.

Table 3 Distribution of $w h$-items with and without negation

\begin{tabular}{|c|c|c|c|c|}
\hline \multicolumn{3}{|l|}{$W h$-item } & \multicolumn{2}{|c|}{ Landing site } \\
\hline & & & No Neg & Neg \\
\hline \multirow[t]{2}{*}{$W h$-nominal } & \multicolumn{2}{|l|}{ In situ } & In situ & In situ \\
\hline & \multicolumn{2}{|l|}{ Moved } & Low focus & High focus \\
\hline \multirow[t]{4}{*}{$W h$-adverbial } & \multirow[t]{2}{*}{ In situ } & Preverbal & In situ & High focus \\
\hline & & Postverbal & In situ & High focus \\
\hline & \multirow[t]{2}{*}{ Moved } & Preverbal & Low focus & High focus \\
\hline & & Postverbal & Low focus & High focus \\
\hline
\end{tabular}

Since there are no data on in-situ $w h$-items preceded by negation, it is reasonable to state that LAC did not allow covert phrasal movement of a wh-phrase. A fronted indefinite phrase can sometimes appear in a position following negation, but then it is always as an NPI, as in Example (54), because negation is the closest licenser. In LAC, whenever negation c-commands a potential wh-phrase, the latter is always interpreted as an NPI. The NPI construction is irrelevant to interrogative wh-phrases, but it does show that negation cannot c-command a wh-phrase that is interpreted as an interrogative. Therefore, I suggest that there is no covert phrasal movement of wh-phrases in LAC.

$\begin{array}{llllllllll}\text { a. 何 } & \text { 不 } & \text { 樹 } & \text { 之 } & \text { 於 } & \text { 無 } & \text { 何 } & \text { 有 } & \text { 之 } & \text { 鄉? } \\ \mathrm{He} & \text { bu } & \text { shu } & \text { zhi } & \text { yu } & {[[\mathrm{wu}} & {\left[\mathrm{he}_{\mathrm{i}}\right.} & \left.\left.\text { you } \mathrm{t}_{\mathrm{i}}\right]\right] & \mathrm{zhi} & \text { xiang]? } \\ \text { why } & \text { not } & \text { plant } & \text { it } & \text { in } & \text { not.exist } & \text { what } & \text { exist } & \text { GEN } & \text { place }\end{array}$
'Why don't you plant it in a place where there isn't anything?' (Zhuangzi $\bullet$ Xiaoyaoyou; Aldridge 2010: 26) 


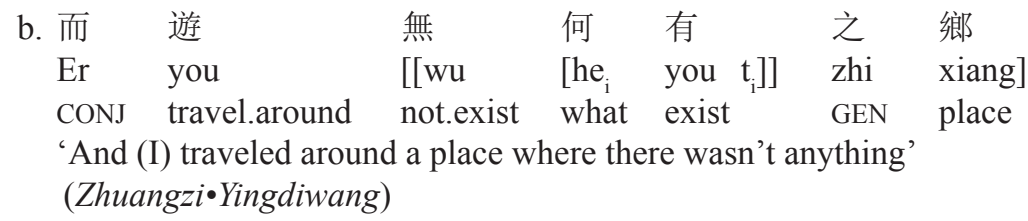

If a $w$-phrase is c-commanded by negation, it is always interpreted as an indefinite, rather than an interrogative. Therefore, in order to get a true wh-interpretation, the $w h$-phrase must undergo overt phrasal movement across negation. This is the Intervention Effect of negation. The landing site for fronted $w h$-phrases, i.e., the High focus position, is still in the c-command domain of a Q-operator but not negation.

Contrary to the fact that negation displays the Intervention Effect in LAC, negation does not show the Intervention Effect in modern Mandarin. Consequently, a negator can take a position between a Q-operator and an in-situ $w$-item bound by this Q-operator, as in Example (55).

Zhangsan bu xiang mai shenme?
Zhangsan not want buy what
'What doesn't Zhangsan want to buy?'
(Kim 2002b: 625)

\section{The intervention effect of focus}

Interestingly, the Intervention Effect of focus phrases does not exist in LAC, which is unexpected, because focus constructions almost never fail to exhibit such a blocking effect on wh-nominals in modern Mandarin, as in Examples (1-4), repeated as Examples (56-59).
a. ? Lili ye kan-le na-ben shu?
Lili also read-ASP which-CL book
b. Na-ben shu Lili ye kan-le?
which-CL book Lili also read-ASP

'Which book did Lili, too, read?'

(57) a. ?? Lian Lili ye kan de dong na-ben shu? even Lili also read DE understand which-CL book

b. Na-ben shu lian Lili ye kan de dong? which-CL book even Lili also read DE understand 'Which book could even Lili understand?'
a. ?* Zhiyou Lili kan-le na-ben shu? only Lili read-ASP which-CL book
b. Na-ben shu zhiyou Lili kan-le?
which-CL book only Lili read-ASP
'Which book did only Lili read?' 


$\begin{array}{cllllll}\text { (59) a. * Shui } & \text { ye } & \text { kan } & \text { bu } & \text { dong } & \text { na-ben } & \text { shu? } \\ \text { who } & \text { also } & \text { read } & \text { not } & \text { understand } & \text { which-CL } & \text { book } \\ \text { b. Na-ben } & \text { shu } & \text { shui } & \text { ye } & \text { kan } & \text { bu } & \text { dong? } \\ \text { which-CL } & \text { book } & \text { who } & \text { also } & \text { read } & \text { not } & \text { understand }\end{array}$

'Which book could no one understand?'

(Kim 2002b: 626)

When subjects are focalized, they do not function as barriers; so, this fact supports the statement that focus does not impose any Intervention Effect in LAC. The reason lies in that wh-phrases undergo clause-internal movement in LAC; so, fronting across the subject would violate the hierarchy of clausal positions (see Section 6.3 for a detailed discussion).

First, in the second question of Example (60a), the LF dependency of a whobject bound by a Q-operator crosses a c-commanding subject DP that is licensed by a focus particle 亦 $y i$ 'also'. ${ }^{16}$ I postulate that both clauses in Example (60a) involve an empty verb 有 you 'have', and the complete counterparts of Example (60a) are instances such as Examples (60b) and (60c) with a derived subjectobject-verb (SOV) order and a fronting marker. In a canonical sentence, the verb you is presumed to be situated between the subject and the direct wh-object 何 罪 he zui 'what sin'. As a VP-internal constituent, the wh-object undergoes obligatory preposing and lands in a preverbal position in the sentence-internal domain, generating the surface structure. I posit that the wh-DP 何罪 he zui in both questions of Example (60a) lands in the Low focus position. Similar to Example (60a), Example (60d) involves a wh-word 何 he 'what' that has fronted to a position preceding the verb, but the focus particle 亦 $y i$ in front of $w h$ fails to create any blocking effect for Q-binding. Despite the insertion of the focus particle 亦 $y i$ on the subject in the second question in Examples (60a) and (60d), the wh-argument still targets the Low focus position below the focus construction, instead of moving past focus to a higher position. As can be seen from Example (60d), the wh-DP can move, so it will front to the High focus position if it needs to. Besides, the wh-DP in Examples $(60 \mathrm{a} / \mathrm{d})$ is not a wh-P construction whose fronting to the High focus position could cause confusion between it and a reason adverbial. Therefore, it is not the case that the wh-DP cannot move, but rather it does not need to, because focus is not a barrier for Q-binding.

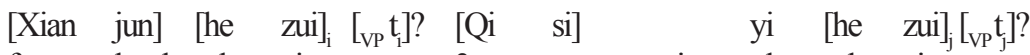 former lord what $\sin$ 3.GEN crown.prince also what sin
a. 先 君 何 罪? 其 嗣 亦何 罪? 'What sin did the former lord (have)? What sin does his crown prince, too, (have)?'
(Zuozhuan $\bullet$ Wengong 7)

\footnotetext{
16 The counterpart of 亦 $y i$ 'also' in modern Mandarin is 也 ye 'also', as in Example (56). Both alsophrases follow and license focus constructions.
} 
b. 其 父有 罪

Qi fu [ [vp you zui]

GEN father have sin

'His father has sin'

(Guоуи•Jinyu 5)

c. 宋何罪之 有?

Song $\quad[\text { he } \quad \text { zui }]_{\mathrm{i}}$ zhi $\quad\left[\begin{array}{lll}\mathrm{VP} & \text { you } & \mathrm{t}_{\mathrm{i}}\end{array}\right]$ ?

Song what sin ZHI have

'What sin does the State of Song have?'

(Mozi•Gongshu)

d. 太子 亦何 如?

Taizi yi he $\quad \mathrm{C}_{\mathrm{VP}}$ ru $\mathrm{t}_{\mathrm{i}}$ ?

crown.prince also what be.like

'What is the crown prince, too, like?'

(Hanfeizi $\bullet$ Neichushuoxia)

Second, the sentence-initial WEI, along with SUO, ${ }^{17}$ may be interpreted as a subject focus-type cleft that expresses exhaustive identification and requires a focus to be assigned to a designated position, i.e., the subject position. That is to say, the subject 君 jun is licensed as a focus by WEI ... SUO, which conveys the meaning 'only' and carries an evaluative presupposition. The simplex $w h$-phrase 何 he functions as a nominal predicate, with an empty preposition, and it is basegenerated postverbally. The in-situ $w h$-item in Example (61) indicates that focus does not block the LF movement of wh-phrases.

$\begin{array}{lllll}\text { 唯 君 } & \text { 所 病 } & \text { 之 } & \text { 何 } & \text { 也? } \\ \text { Wei jun } & \text { suo bing } & \text { zhi } & {\left[_{\text {pp }} \text { he }\right]} & \text { ye? } \\ \text { WEI Your.Majesty } & \text { SUO have.disease.of } & \text { 3.OBJ } & \text { what } & \text { DECL } \\ \text { '(For) what is it only Your Majesty who has this disease?' } & & \\ \text { (Zhuangzi } \bullet \text { Xuwugui) }\end{array}$

17 It is pointed out by Aldridge $(2009,2013)$ that 所 suo can be used to relativize on a VP-internal element by means of binding a gap inside the VP as a verbal functional head, as well as to nominalize an embedded clause, generating a reduced relative clause with a genitive subject. I hypothesize that in addition to these two functions, SUO can also form a subject focus-type cleft with 唯 WEI, as in Examples (61) and (i).
(i) a. 唯子所 利
[Wei zi] [suo li]
'it is only you who decide'
$($ Guоуи $\bullet$ Luуихіа)
WEI you SUO decide
b. 唯執政所置之
[Wei zhizheng] [suo zhi zhi]
WEI ruler SUO dispose 3.OBJ
'It is only the ruler who disposes him'
(Zuozhuan•Zhaogong 7)


Third, the semantic operator 又 you 'also; again' is an association with focus (proposed by Jackendoff [1972], which applies to negation, focus-sensitive particles, and yes-no questions), but it does not trigger further preposing of a whconstituent. In the parallel structures in Example (62), the $w h$-word 惡 $w u$ 'where' in both questions fronts to the same position. In the former question, the whcomplement of the preposition 乎 $h u$ 'from' rises out of a postverbal adjunct PP to the Low focus position. In the latter question, an association with focus 又 you 'also; again' has been inserted, but the wh-complement 惡 $w u$ does not land in a higher position across the association with focus.

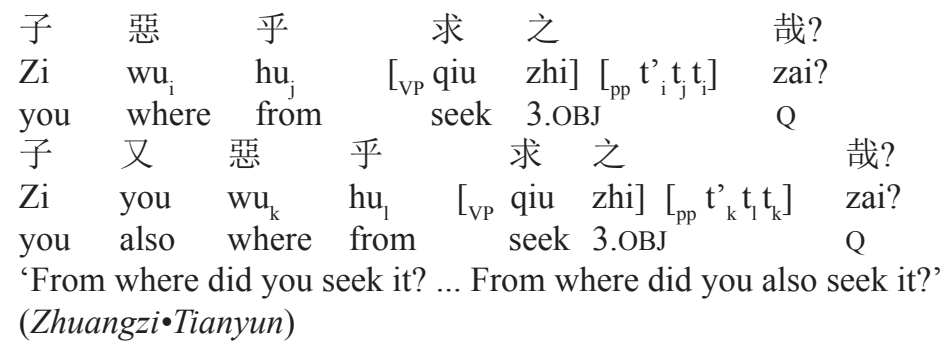

Fourth, 尚 shang 'even' in Example (63) focalizes on the object 何 he 'what', which fronts from a postverbal position to the medial domain. The preposed whobject lands in a position c-commanded by the "even"-focus, instead of moving across the focus.

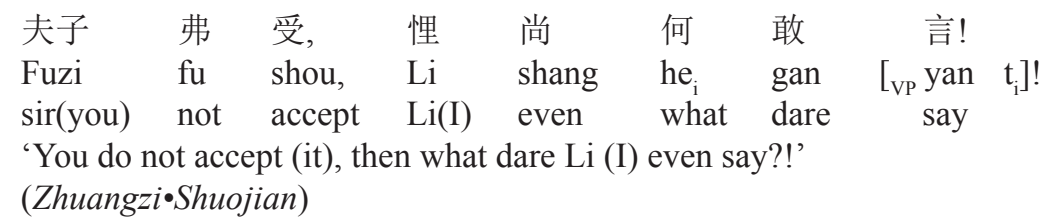

Even if Example (61) may be invalidated by the locality constraint, namely, whmovement cannot pass a focus phrase in the subject position and hence target $\mathrm{CP}$, the latter two pieces of evidence undeniably justify the absence of the Intervention Effect caused by focus expressions. Examples (60d) and (63) show that the $w h_{\mathrm{Foc}}{ }^{*}(\mathrm{Neg})$ Foc configuration is unattested, but they cannot rule out the possibility for focus constructions between the tense phrase (TP) and VP to block the LF movement of nominal and adverbial wh-phrases. The preposing of the focalized $w h$-words $w u$ in Example (62) and he in Examples (60d) and (63) shows that there is a domain between the subject and VP for the moved $w h$-items, so wh has the alternatives to either precede or follow the focus-phrase "also"/"even". However, the $w h$ lands in a position following the focus, which means that focus is not a barrier. I posit that it is impossible (1) for a VP-internal wh-DP or a wh-adverbial/predicate base-generated postverbally to move to the High focus position when c-commanded by a preposed non-wh-constituent in the Low focus position or (2) for a postverbal wh-adverbial/predicate to rise to the High or Low 
focus position when c-commanded by a focus phrase remaining in its postverbal base position. ${ }^{18}$

As can be seen from Examples (60a/d), (61), (62), and (63), despite the presence of focus or association with focus constructions, all wh-elements are c-commanded by focalized subjects: the nominal wh-arguments 何 he, 何罪 he zui, and 惡 $w u$ appear in the Low focus position and the predicative $w h$-phrase 何 he remains in situ. So, it is reasonable to claim that a focus structure does not function as a barrier for Q-binding between a Q-operator and a function variable, as there are felicitous data concerning Foc ... [+wh]. Therefore, an interesting observation is that in modern Mandarin, focus structures display the Intervention Effect, yet in LAC, they fail to induce the Intervention Effect.

This asymmetry seems to violate the Uniformitarian Principle that the same principles applicable to a synchronic grammar are also suitable for previous stages of that language (Hale 1998, Hale 2007). Nonetheless, I hypothesize that the reason why focus does not impose the Intervention Effect in LAC is because focus and negation have different features.

In the context of focus, if an XP [+wh] fronts (to a position below focus), the fronting is introduced by clause-internal overt movement. Next, the $[+w h]$

18 Focus constructions in LAC do not necessarily front to a preverbal position. In Example (i), objects are focalized by the only-phrase, and the foci remain in their base positions within the $v \mathrm{P}$. SUO in this structure is sometimes preceded by $\mathrm{ZHI}$, which is a marker for explicit subordination [Example (ia)].

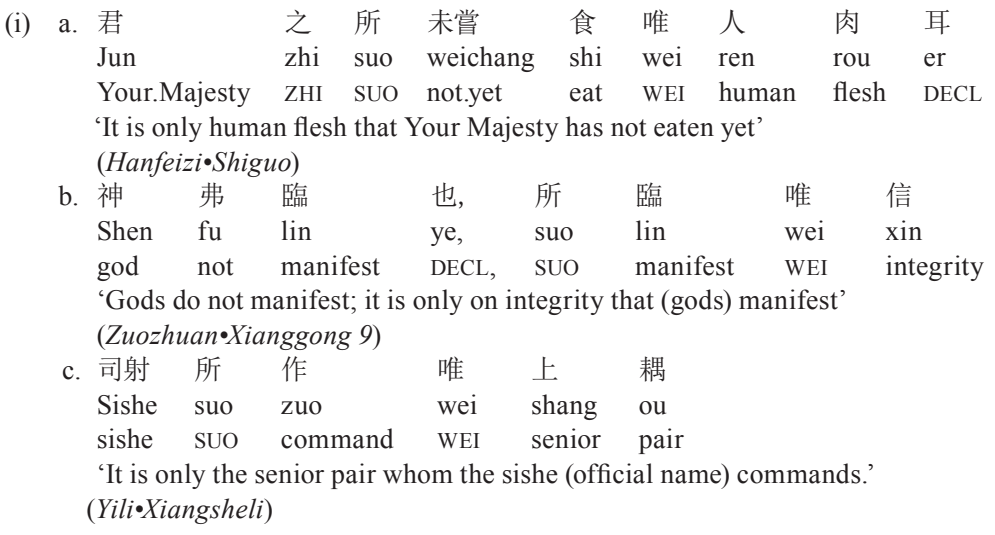

This configuration is preserved in modern Mandarin, with SUO being optional, as exemplified in Example (ii). $\begin{array}{llllllll}\text { (ii) Women } & \text { (suo) } & \text { tingshuo } & \text { de } & \text { zhi } & \text { shi } & \text { bufen } & \text { zhenxiang. } \\ \text { 1PL } & \text { (SUO) } & \text { hear } & \text { DE } & \text { only be } & \text { part truth }\end{array}$ 'What we heard about is only part of the truth.' 
feature is interpreted by feature movement. If an XP $[+w h]$ does not front, it is interpreted by feature movement. In LAC, feature movement is subject to the Intervention Effect. If due to obligatory wh-preposing, a wh-phrase moves to a focus position below the focus phrase (as in Examples [60d/62/63]) driven by the $[+\mathrm{Foc}]$ feature and stops there, then it is interpreted via feature movement that is subject to the Intervention Effect, as in Example (64a). Based on available data, it is always the subject that is focalized, and the landing site for the preposed $w h$-phrase is the Low focus position. I hypothesize that Q is around $\mathrm{CP}$ and the focalized subject intervenes between $\mathrm{Q}$ and $w h-\mathrm{XP}$. When a $w h$-phrase stays in situ, its $[+w h]$ feature is interpreted by feature movement, as in Example (64b).

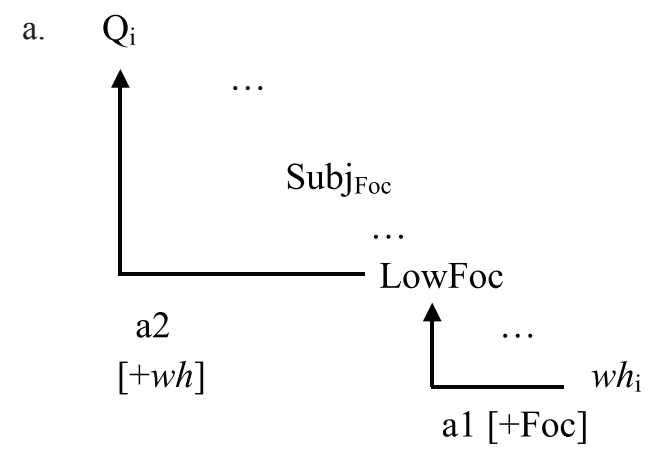

a1: overt phrasal movement; a2: feature movement

b. $\mathrm{Q}_{\mathrm{i}}$

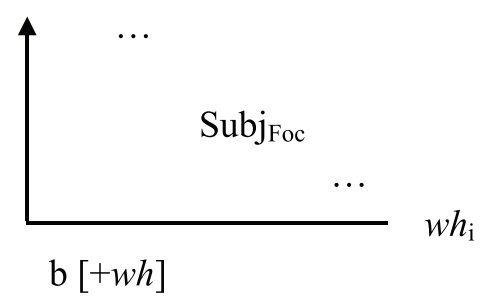

$\mathrm{b}$ : feature movement

As suggested by Rizzi (2001a, 2001b), Relativized Minimality only holds within classes of features, but not across them. Both $w h$ and Neg are quantificational features occupying an $\mathrm{A}^{\prime}$-specifier position, but Foc displays a focus feature that is distinct from "modifier features". Both quantificational and modifier features are specifier-licensing features in the $\mathrm{A}^{\prime}$-system, but these two classes of features contain different elements (Examples [65/66]). So, it is plausible that focus does not belong to the class of quantificational features but to another subclass of discourse-related or pragmatic $\mathrm{A}^{\prime}$-features. 
Therefore, focus cannot determine a Minimality effect on the wh-chain, but negation can.

(65) Quantificational: wh, Neg, amount/frequency, ...

(66) Modifier: evaluative, epistemic, amount/frequency, manner, ... (Rizzi 2001b: 104)

The Intervention Effect occurs because the dependency between $\mathrm{X}$ and $\mathrm{Y}$ is blocked by an intervening barrier $\mathrm{Z}$ that bears the same feature $[\alpha]$ as $\mathrm{X}$ and $\mathrm{Y}$ (Yang 2007).

(67) $*\left[\ldots X_{[\alpha]} \ldots\left[\ldots Z_{[\alpha]} \ldots\left[\ldots Y_{[\alpha]} \ldots\right]\right]\right]$

(Yang 2007: 104)

If the schema in Example (67) is used to indicate the Intervention Effect of negation in LAC, $\mathrm{Y}$ is a function variable $w h$-phrase (either a DP or an AdvP), and $\mathrm{X}$ is its Q-operator. Since the Q-binding between $\mathrm{X}$ and $\mathrm{Y}$ is blocked by negation $(\mathrm{Z})$, which bears the same quantificational feature [Quant], ungrammaticality results in the construction Neg ... [+wh] (Example [68]).

$$
*\left[\mathrm{Q}-\mathrm{Op}_{\mathrm{i}}\left[\mathrm{C}_{\text {[Quant }]}\left[\ldots \mathrm{Neg}_{[\mathrm{Quant}]} \ldots\left[\ldots w h-\mathrm{XP}_{\text {[Quant }]} \ldots\right]\right]\right]\right]
$$

Focus phrases in LAC, however, do not impose the Intervention Effect on whinterrogatives. Both the function variable wh-phrase (Y) and its Q-operator (X) bear the quantificational feature [Quant], yet the intervening focus bears the modifier feature [Mod]. The dependency between the function variable whphrase (Y) and its Q-operator (X) is not blocked by a focus phrase (Z) that bears a different, modifier feature. Therefore, the structure Foc ... [+wh] is felicitous. Thus, the schema in Example (69) shows the lack of the Intervention Effect of focus in LAC.

$$
\left[\mathrm{Q}-\mathrm{Op}_{\mathrm{i}}\left[\mathrm{C}_{[\mathrm{Q} \text { uant }}\left[\ldots \mathrm{Foc}_{[\mathrm{Mod}]} \ldots\left[\ldots w h-\mathrm{XP}_{[\text {Quant }]} \ldots\right]\right]\right]\right]
$$

Therefore, I state that the reason why focus does not impose the Intervention Effect in LAC is attributable to the fact that focus and negation have different features. Both wh and Neg are quantificational features, so Neg can block the Q-binding between $w h$ and its operator. Focus, however, bears a different modifier feature from $w h$, so focus cannot block the Q-binding of $w h$.

\section{The intervention effect of quantifiers}

Contrary to the fact that focus phrases display the Intervention Effect, quantifiers do not impose any Intervention Effect in modern Mandarin. As a consequence, a quantified structure can take a position between a Q-operator and an in-situ wh-item bound by this Q-operator, as in Examples (70a/b), which contain an ordinary quantifier NP and a frequency adverbial, respectively (Kim 2002b). It is notable that the quantifier dou 'all' (as in Example [70a]) only quantifies to its left (Cheng 1995). 
(70)

a. Meigeren dou mai-le shenme? ${ }^{19}$
everyone all buy-ASP what
'What did everyone buy?'

b. Zhangsan changchang

Zhangsan often buy what

'What does Zhangsan often buy?'

(Kim 2002b: 625)

Parallel to their counterparts in modern Mandarin, quantificational expressions in LAC do not seem to be barriers for Q-binding, in that wh-constituents can appear under quantifiers and do not have to undergo overt movement in order to get bound by a Q-operator. Examples (71a) and (71b) contain an ordinary quantifier 皆 jie 'all' and a frequency adverbial 常 chang 'often', respectively; the counterparts of jie 'all' and chang 'often' in modern Mandarin are dou and chang(chang) in Examples (70a/b). Example (71a) involves the rising of a prepositional complement 何 he out of a $v$ P-internal PP to the Low focus position, triggered by obligatory wh-fronting. Likewise, the same wh-word he in Example (71b) fronts out of the "high" adverbial "why" to the High focus position; Example (71b) additionally involves VP-fronting to the Internal topic position between TP and the High focus position, and the tree diagram of the embedded clause is in Example (71c). ${ }^{20}$ The $w h$-word in both examples is still c-commanded by a quantifier at S-structure after fronting, which means quantificational elements do not create any blocking effect on LF movement of wh-phrases.
a. 皆何以
以 稳
Jie he yi $_{\mathrm{j}}\left[\mathrm{PP}_{\mathrm{PP}} \mathrm{t}_{\mathrm{i}} \mathrm{t}_{\mathrm{j}} \mathrm{t}_{\mathrm{i}}\right]$
稱人?
all what with
cheng ren]?
address person

'With what do (we) all address those people?'

(Gongyangzhuan $\bullet$ Huangong 15 )

$\begin{array}{llllll}\text { b. 原 } & \text { 聞 } & \text { 古 } & \text { 之 } & \text { 明 } & \text { 主 } \\ \text { Yuan } & \text { wen } & \text { [gu } & \text { zhi } & \text { ming } & \text { zhu] } \\ \text { want } & \text { hear } & \text { ancient } & \text { GEN } & \text { wise } & \text { lord }\end{array}$

19 This question allows a pair-list answer such as in Example (i) (Aoun and Li 1993).

$\begin{array}{lllll}\text { (i) } & \text { shangsan } & \text { mai-le } & \text { shu, Lisi mai-le } & \text { zazhi, } \\ \text { Zhangsan } & \text { buy-AsP } & \text { book, Lisi buy-ASP } & \text { magazine, } \\ \text { Wangwu } & \text { mai-le } & \text { baozhi } & & \\ \text { Wangwu } & \text { buy-AsP } & \text { newspapers } & & \\ \text { 'Zhangsan bought books, Lisi magazines, Wangwu newspapers ...' }\end{array}$

20 In the embedded clause, he $y i$ 'what for' is a reason adverbial, so it fronts to the High focus position. Since VP-fronting targets a position between the subject and the High focus position, it can only be the Internal topic position according to the clausal positions suggested in the template in Example (40), although the Internal topic position is usually occupied by a wh-constituent, instead of a non-wh one. 


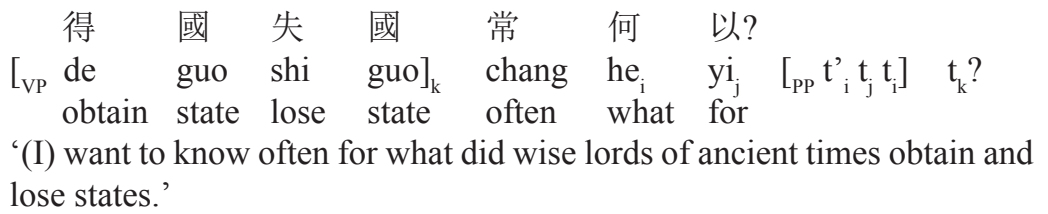

\section{(Hanfeizi $\bullet$ Shiguo)}

c.

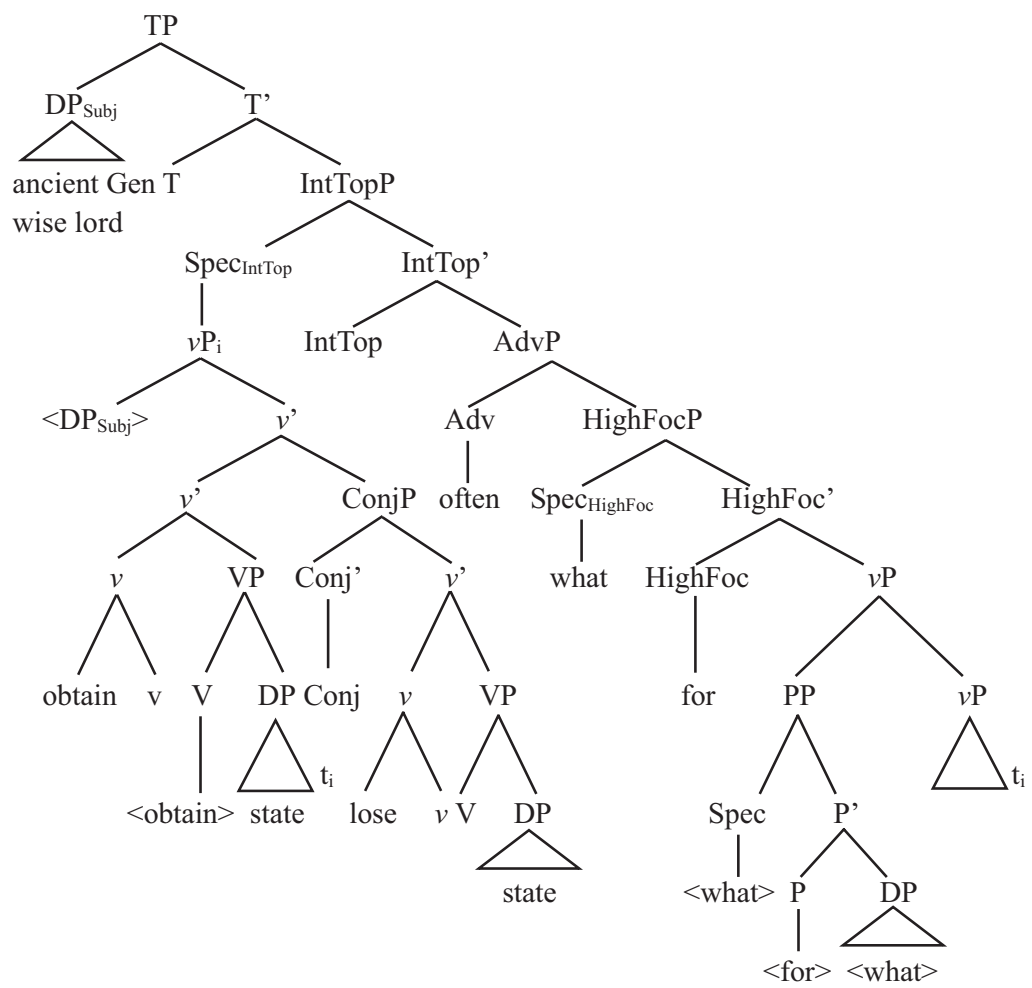

The wh-indefinite 何 he 'what' in 無何有 wu he you (see Example [73] below) has no quantificational force; as a variable, it has to be bound by an operator (Pesetsky 1987). Since he 'what' in wu he you is an NPI, whose licensing is feature movement (Guerzoni 2006), it is supposed to be sensitive to the Intervention Effect. As argued by Linebarger (1987), an operator intervening between an NPI and its licensor gives rise to ungrammaticality, as in Example (72).

(72) a. Mary didn’t wear any earrings to every party.

b. *NOT $\gg$ > every $>$ any

NPI-licensing is in a close relation with intervention in wh-questions, and NPI "blocking expressions" largely overlap with interveners identified in whquestions. Two types of the Intervention Effect, LF Intervention Effect on $w h$-in-situ and NPI licensing, can be analyzed by a unified approach: both the 
licensing of $w h$-in-situ and that of NPIs are focus-sensitive and an intervening element with the [+Focus] feature blocks the licensing (Kim 2002a; Guerzoni 2006). Like in wh-questions, an intervention effect concerning NPIs arises only in feature movement, but never in covert phrasal movement. The explanation is natural: feature movement is the syntactic correlate of focus interpretations; a focus interpretation is involved in NPI-licensing (Beck 2006). The verb you 'exist, have' intervening between the licensor and the licensee (the NPI) in the underlying structure does not carry the matching feature [+Foc]; so, it does not trigger any special licensing or blocking issue; as for the rising of the wh-word $h e$, it is caused by obligatory $w h$-preposing in LAC (Examples [73a-b]). Despite the presence of a nominal quantifier 無 $w u$ 'not exist; no' and the prediction that the licensing of the NPI he should be sensitive to the Intervention Effect, NPI licensing is still realized. Similarly, in 無何 wu he 'no what' ('nothing') (Example [73c]) and 無幾何 wu jihe 'no how many' ('not long') (Example $[73 \mathrm{~d}]$ ), the binding between the NPI he/jihe and their operators should have been blocked by the quantifier $w u$ 'no', but the Intervention Effect does not arise. Therefore, it can be concluded that quantificational expressions do not introduce the Intervention Effect.

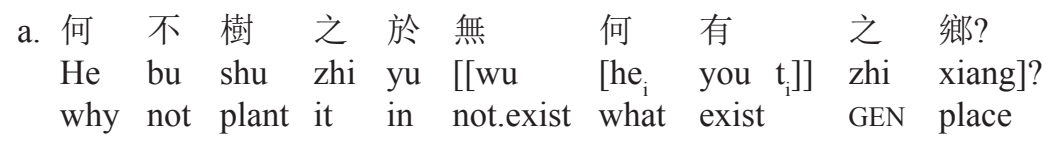
'Why don't you plant it in a place where there isn't anything?' (Zhuangzi $\bullet$ Xiaoyaoyou; Aldridge 2010: 26)

$\begin{array}{lllllll}\text { b. 而 } & \text { 遊 } & \text { 無 } & \text { 何 } & \text { 有 } & \text { 之 } & \text { 鄉 } \\ \text { Er } & \text { you } & {[[\mathrm{wu}} & {\left[\mathrm{he}_{\mathrm{i}}\right.} & \text { you t } \mathrm{t}]] & \mathrm{zhi} & \text { xiang }] \\ \text { CONJ } & \text { travel.around } & \text { not.exist } & \text { what } & \text { exist } & \text { GEN } & \text { place }\end{array}$
'And (I) traveled around a place where there wasn't anything.' (Zhuangzi $\bullet$ Yingdiwang)

c. 曰: 是 何 也? 曰: 無 何 也! Yue: Shi he ye? Yue: $\mathrm{Wu}$ he ye! say this what $Q$ say no what DECL '(People) asked: "What is this?" I said: "Nothing!", (Xunzi•Tianlun)

$\begin{array}{lllll}\text { d. 無 } & \text { 幾何, } & \text { 疾 } & \text { 乃 } & \text { 止 } \\ \mathrm{Wu} & \text { jihe, } & \text { ji } & \text { nai } & \text { zhi } \\ \text { no } & \text { how.many } & \text { disease } & \text { just } & \text { cease }\end{array}$

'(He) recovered from the disease soon.' (Lit. 'Not long, the disease just ceased.')

(Lüshichunqiu $\bullet$ Jixiaji)

In the context of quantificational expressions, if an XP [+wh] fronts to a position below the quantifier via clause-internal overt movement, the $[+w h]$ feature is then interpreted by feature movement that is subject to the Intervention Effect. For instance, due to obligatory wh-preposing, a wh-phrase in Example (74) moves 
to a focus position below the quantificational phrase driven by [+Foc] feature and stops there. In available data, it is always the subject that is quantified, and the landing site for the preposed wh-phrase is the High or Low focus position (Examples $[74 \mathrm{a} / \mathrm{b}]$ ). I hypothesize that $\mathrm{Q}$ is around $\mathrm{CP}$, and the quantificational subject intervenes between $\mathrm{Q}$ and the $w h$-XP. The fronted $w h$ is interpreted via feature movement that is subject to the Intervention Effect. If an XP [+wh] does not front, it is directly interpreted by feature movement, as in Example (74c).

(74) a. Q

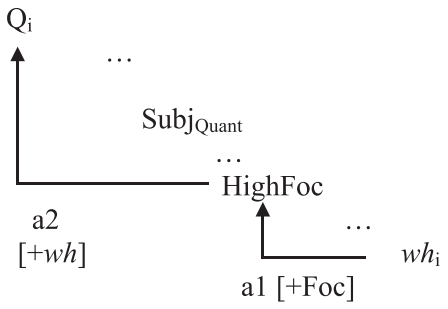

a1: overt phrasal movement; a2: feature movement

b. $\quad Q_{1}$

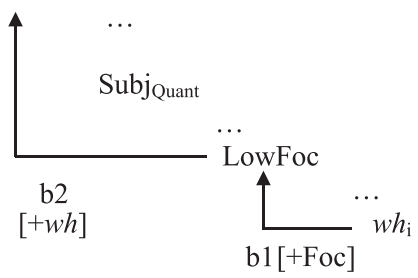

b1: overt phrasal movement; b2: feature movement

c. $\mathrm{Q}_{\mathrm{i}}$

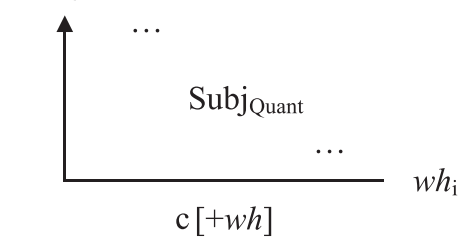

c: feature movement

I postulate that quantificational expressions do not share the same feature with Neg or $w h$ and so, different from negation that triggers the Intervention Effect by blocking the Q-binding between $w h$ and its operator, quantifiers do not have the Intervention Effect on $w h$-phrases. Since the Q-binding between the $w h$-variable and its Q-operator is not blocked by a quantifier that bears different features from wh, ungrammaticality does not result in a construction with a quantifier preceding an XP [+wh], as in Example (71).

Alternatively, it is possible that quantifiers do share the same quantificational feature with negation and $w h$, so quantifiers should trigger the Intervention Effect as well, parallel to negation. The reason why quantifiers fail to display the Intervention 
Effect is that when quantifiers are involved, there is always covert phrasal movement that is not subject to the Intervention Effect. If an XP $[+w h]$ is c-commanded by a quantifier and the XP fronts to a higher position (but is still lower than the quantifier), the XP undergoes overt phrasal movement and then covert phrasal movement. If an XP $[+w h]$ is c-commanded by a quantifier and the XP stays in situ, the XP only undergoes covert phrasal movement. Since covert phrasal movement is not subject to the Intervention Effect, despite the fact that quantifiers and wh share the same feature, quantifiers can intervene between wh and $\mathrm{Q}$ without triggering ungrammaticality. However, I do not take this option because it is difficult to explain why $w h$ feature movement applies to constructions with negation and focus phrases, but constructions with quantifiers have to adopt covert phrasal movement.

For the sake of consistency, I state that $w h$, in the context of quantifiers, undergoes feature movement, similar to its counterpart in the context of negation and foci. Quantifiers fail to trigger the Intervention Effect on wh because quantifiers do not have the same feature as $w h$.

\section{Conditions of the Intervention Effect}

In this section, I account for the presence/absence of the Intervention Effect in LAC, as well as the diachronic asymmetry between LAC and modern Mandarin. I propose three requirements for the Intervention Effect: (1) interrogativity of whitems; (2) the possibility of feature wh-movement; and (3) a hierarchy of clausal positions. If and only if all three conditions are satisfied can the Intervention Effect take place, and this applies to both LAC and modern Mandarin.

\subsection{Interrogativity of $w h$-constituents}

The first condition of the Intervention Effect in LAC is that wh-constituents have to be interrogative. In Examples $(75 \mathrm{a}-\mathrm{d})$, wh-indefinites follow the negator 無 $w u$ 'not have' without moving to a preceding position, thus they consequently become NPIs. However, these instances involve obligatory wh-in-situ, namely, wh-constituents acting as the second complement of ditransitive verbs 奈/若/如 nai/ruo/ru 'treat', so it is difficult to judge which factor circumvents the Intervention Effect: the noninterrogative interpretation, or obligatory wh-in-situ, or both. Similarly, 末 mo in Example (75d) is a negative particle mostly found in the Analects (Pulleyblank 1995). As can be seen from Example (75e), in an NPI structure, the first complement of the ditransitive verb can move to a higher position preceding negation, so it could be the obligatory wh-in-situ of the second argument that prevents $w h$ from fronting.

$\begin{array}{llllllll}\text { a. 孤 } & \text { 無 } & \text { 奈 } & \text { 越 } & \text { 之 } & \text { 先 } & \text { 君 } & \text { 何 } \\ \mathrm{Gu} & \mathrm{wu} & \text { nai } & \text { [yue } & \text { zhi } & \text { xian } & \text { jun] } & \text { he } \\ \mathrm{I} & \text { not.have } & \text { treat } & \text { Yue } & \text { GEN } & \text { former } & \text { lord } & \text { what }\end{array}$

'There was nothing I could do about the former lord of Yue.'

(Gиоуи•Wиуu; Aldridge 2010: 25) 
$\begin{array}{llll}\text { b. 無 } & \text { 若 } & \text { 政 } & \text { 何 } \\ \mathrm{Wu} & \text { ruo } & \text { zheng } & \text { he } \\ \text { not.have } & \text { treat } & \text { ordinance } & \text { what }\end{array}$

'There is nothing (the ruler) can do about the ordinances'

$($ Guoyu $\bullet$ Jinyu $)$

c. 亦無 如之 何 矣

Yi wu ru zhi he yi

also not.have treat 3.OBJ what PERF

'There is nothing (they) can do about it anymore'

(Liji•Daxue)

d. 吾末 如之何 也已矣 ${ }^{21}$

Wu mo $\left[_{\mathrm{VP}} \mathrm{ru}\right.$ zhi he $]$ yeyiyi

I NEG treat 3.OBJ what SFP

'I do not (know) how to treat him then'

(Analects $\bullet$ Weilinggong)

e. 知其不可 奈 何

Zhi $\mathrm{qi}_{\mathrm{i}}$ bu ke $\quad$ VP $_{\text {nai }} \mathrm{t}_{\mathrm{i}}$ he $]$

know 3.OBJ not can treat what

而安之若命

er an zhi ruo ming

CONJ embrace 3.OBJ as destiny

'(they) know there is nothing (they) can do about it, so (they) embrace it as the destiny'

(Zhuangzi $\bullet$ Renjianshi)

The effect of noninterrogativeness is more self-evident if we take a look at Examples (76a-b). In these examples, an NPI $w h$-word 何 he has fronted within an embedded clause, but the licenser is in a higher domain (Aldridge 2010), so the focalized whelement is still below negation; in other words, the blocking effect does not apply to this $w h$-indefinite. There is no denying the fact that another $w h$-indefinite 誰 shui in Example (76c) does front to a position preceding negation, yet this example is a conditional clause, the properties of which need further investigation. There must be other independent reason(s) that trigger the $w h$-fronting.

$\begin{array}{llllllllll}\text { a. 何 } & \text { 不 } & \text { 樹 } & \text { 之 } & \text { 於 } & \text { 無 } & \text { 何 } & \text { 有 } & \text { 之 } & \text { 鄉? } \\ \mathrm{He} & \text { bu } & \text { shu } & \text { zhi } & \text { yu } & {[[\mathrm{wu}} & {\left[\mathrm{he}_{\mathrm{i}}\right.} & \left.\left.\text { you } \mathrm{t}_{\mathrm{i}}\right]\right] & \mathrm{zhi} & \text { xiang }] \text { ? } \\ \text { why not } & \text { plant } & \text { it } & \text { in } & \text { not.exist } & \text { what } & \text { exist } & \text { GEN } & \text { place }\end{array}$
'Why don't you plant it in a place where there isn't anything?'

(Zhuangzi•Xiaoyaoyou; Aldridge 2010: 26)

21 This sentence final particle 已 yi originated from a verb 'stop, finish' (as in Example [75d]) and later developed into a perfect aspect marker (Pulleyblank 1995: 115). The sentence final particle 也已矣 ye yi yi conveys a sense of resignation and is used to express the speaker's subjective mood, i.e., new realization of a (changed) situation (Yap et al. 2010). 
$\begin{array}{lllllll}\text { b. 而 } & \text { 遊 } & \text { 無 } & \text { 何 } & \text { 有 } & \text { 之 } & \text { 鄉 } \\ \text { Er } & \text { you } & {[[w u} & {\left[\mathrm{he}_{\mathrm{i}}\right.} & \left.\left.\text { you } \mathrm{t}_{\mathrm{i}}\right]\right] & \mathrm{zhi} & \text { xiang }] \\ \text { CONJ } & \text { travel.around } & \text { not.exist } & \text { what } & \text { exist } & \text { GEN } & \text { place }\end{array}$

'And (I) traveled around a place where there wasn't anything' (Zhuangzi $\bullet$ Yingdiwang)

c. 誰之不如, 可以求之

Shui $_{\mathrm{i}}$ zhi bu [VP $_{\mathrm{ru}} \mathrm{ru}_{\mathrm{i}}$, keyi qiu zhi who ZHI not compare can follow 3.OBJ

'If you don't measure up to someone, you can follow him'

(Guоуи•Jinyu 6; Aldridge 2010: 26)

The fact that the Intervention Effect of negation does not apply to wh-indefinites is not surprising: the blocking effect in the sense of Beck 1996a and Beck and Kim 1997 requires a Q-operator and a function variable bound by that Q-operator. When functioning as a polarity item, a wh-constituent does not involve Q-binding, so it may occupy a position lower than negation (which is a barrier for an interrogative $w h$ phrase as a function variable), without undergoing further fronting. This explanation also applies to the observation that negation in LAC does not affect a non-whconstituent: a pronominal object may rise to a focalized position below negation or stay in its VP-internal base position, as in Examples (77a) and (77b), respectively.
a. 余不 女 忍殺
$\mathrm{Yu} \quad$ bu $\mathrm{ru}_{\mathrm{i}}$ ren $\left[\mathrm{VP}_{\mathrm{p}}\right.$ sha $\left.\mathrm{t}_{\mathrm{i}}\right]$
I not you bear kill
'I cannot bear to kill you.'
(Zuozhuan•Zhaogong 1)
$\begin{array}{lllll}\text { b. 吾 } & \text { 不 } & \text { 可以 } & \text { 僭 } & \text { 之 } \\ \mathrm{Wu} & \text { bu } & \text { keyi } & \text { jian } & \text { zhi } \\ \text { I } & \text { not } & \text { can } & \text { arrogate } & \text { 3.OBJ }\end{array}$
'I must not arrogate it.' (Lit. 'I cannot arrogate it')
(Zuozhuan•Aigong 5)

\subsection{Feature movement}

The second condition of the Intervention Effect is that wh-constituents should be permitted to undergo feature movement, instead of being restricted to covert phrasal movement.

Following Beck (2006), I conjecture that wh-phrases that are insensitive to interveners undergo covert phrasal movement at LF, past the interveners. In a multiple question (Example [78a]), the $w h$-phrase is sensitive to superiority. In the LF for this question (Example [79b]), the in-situ wh moves covertly. As a consequence, inserting a focus intervener does not cause infelicity (Example [79]) (Pesetsky 2000; Beck 2006).

(78) a. Who did John introduce to whom?

b. $\left[\mathrm{Q}_{1,2}\left[\mathrm{who}_{1}\left[4\left[\mathrm{whom}_{2}[5[\mathrm{did}[\mathrm{John}\right.\right.\right.\right.$ introduce t4 to t5]]]]]]] 
(79) a. Who did only John introduce to whom?

b. $\left[_{\mathrm{Z}} \mathrm{Q}_{1,2}\left[\right.\right.$ who $_{1}\left[4\right.$ whom $_{2}\left[5\left[\right.\right.$ did $\left[_{\mathrm{X}}\right.$ only ${ }_{\mathrm{C}}\left[\sim \mathrm{C}\left[\mathrm{John}_{\mathrm{F} 3}\right.\right.$ introduce t4 to t5]]]]]]]]]

c. $[[\mathrm{X}]]^{\mathrm{g}}=[[\mathrm{X}]]^{\mathrm{g}, \mathrm{h}}=[[\mathrm{only}]](\mathrm{g}(\mathrm{C}))(\lambda \mathrm{w}$. John intro. $\mathrm{g}(4)$ to $\mathrm{g}(5))$

$[[\mathrm{Z}]]^{\mathrm{g}}=\{$ that only john introduced $\mathrm{x}$ to $\mathrm{y} \mid \mathrm{x}, \mathrm{y}$ individuals $\}$

In LAC, if an XP [+wh] can front, the fronting is either introduced by clauseinternal overt movement, or the $[+w h]$ feature is interpreted by feature movement. The latter is subject to the Intervention Effect, yet the former is not subject to the Intervention Effect. If an XP [+wh] cannot front, namely, under the situation of obligatory $w h$-in-situ, it is interpreted by feature movement.

I hypothesize that $\mathrm{Q}$ is around $\mathrm{CP}$ and negation intervenes between $\mathrm{Q}$ and a $w h$-XP (as in Example [80]), and there are wh-interpretation and focus movement. For feature movement, if a $w h$-XP could move but failed to move, ungrammaticality would arise. The reason is that when feature movement applies, the interpretation of the $w h$-XP is blocked by the Intervention Effect. So, a wh-phrase that has the option to front will front to a focus position driven by the [+Foc] feature, within which wh undergoes feature movement to Q, as in Example (80a). In terms of overt phrasal movement, if a $w h$-phrase moves to a focus position above Neg due to focus feature and stops there, then it is interpreted via feature movement that is subject to the Intervention Effect. In this situation, no ungrammaticality results, as in Example (80b). However, if a wh-XP undergoes overt phrasal movement to a position lower than negation, the example should be bad due to the NIB (Example [80c]). Consequently, wh has to move again to a position above negation and get the interpretation via feature movement. Alternatively, the wh-phrase moves directly to a focus position above negation, as in the previously described derivation. With respect to examples using the repair strategy (Kim 2002b, Kim 2005, Kim 2006), a wh-XP first fronts overtly to a focus position below negation driven by [+Foc] feature. Since, in this position, the Q-binding is blocked by the intervening negation, the $w h$-XP has to rise overtly again to another focus position above negation, also driven by [+Foc] feature, and this is the repair strategy. After landing in its final position, which is the focus position above negation, the $w h$-XP is interpreted by feature movement (Example [80d]).

(80) a.

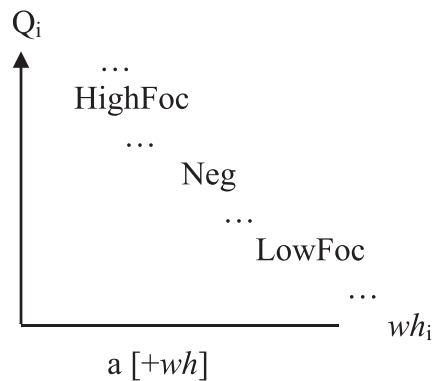

a: feature movement 
b. $\mathrm{Q}_{\mathrm{i}}$

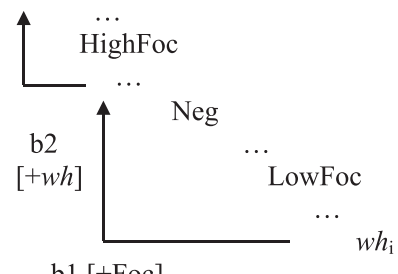

b1 [+Foc]

b1: overt phrasal movement; b2: feature movement

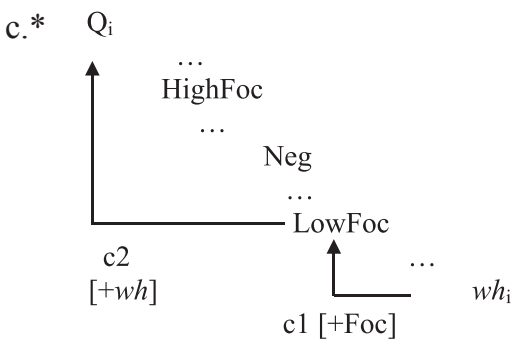

c1: overt phrasal movement; $\mathrm{c} 2$ : feature movement

d.

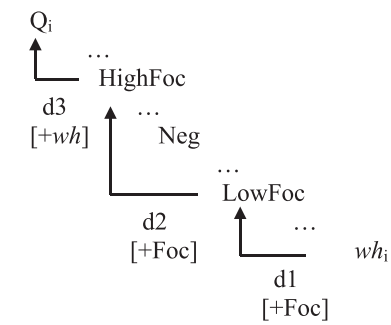

d1: overt phrasal movement; d2: overt phrasal movement;

d3: feature movement

It is notable that if a $w h$-phrase could undergo overt phrasal movement but did not move (Example [81a]), or a fronted $w h$-phrase failed to land in a focus position that is high enough (i.e., higher than negation) (Example [81b]), the sentence would be ungrammatical. The prediction is borne out, as no such data are ever attested, i.e., no wh-in-situ or fronted wh in the presence of a barrier in a preceding position are found.

(81) a.* ${ }^{*} Q_{i}$

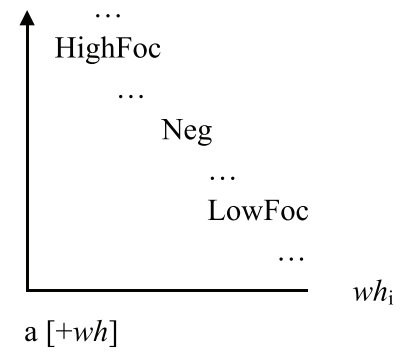

a: covert phrasal movement 


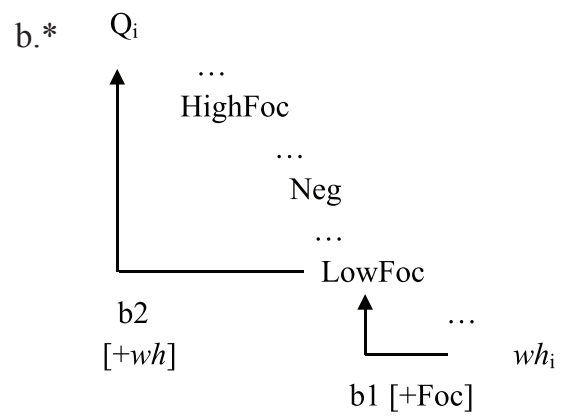

b1: overt phrasal movement; b2: covert phrasal movement

Although the illustrations in Example (82) seem to be counterexamples, they involve an NPI construction that is irrelevant to a $w h$-interrogative. Therefore, it is safe to conclude that LAC does not allow *Neg ... [+wh] configuration; so, there is no covert phrasal movement.

$\begin{array}{llllllllll}\text { a. 何 } & \text { 不 } & \text { 樹 } & \text { 之 } & \text { 於 } & \text { 無 } & \text { 何 } & \text { 有 } & \text { 之 } & \text { 鄉? } \\ \mathrm{He} & \text { bu } & \text { shu } & \text { zhi } & \text { yu } & {\left[\left[\mathrm{wu}^{2}\right.\right.} & {\left[\mathrm{he}_{\mathrm{i}}\right.} & \left.\left.\text { you } \mathrm{t}_{\mathrm{i}}\right]\right] & \mathrm{zhi} & \text { xiang }] \text { ? } \\ \text { why } & \text { not } & \text { plant } & \text { it } & \text { in } & \text { not.exist } & \text { what } & \text { exist } & \text { GEN } & \text { place }\end{array}$
'Why don't you plant it in a place where there isn't anything?' (Zhuangzi•Xiaoyaoyou; Aldridge 2010: 26)

b. 而遊 Er you CONJ travel.around $\begin{array}{lllll}\text { 無 } & \text { 何 } & \text { 有 } & \text { 之 } & \text { 鄉 } \\ {[\text { ww }} & {\left[\text { he }_{\mathrm{i}}\right.} & \left.\left.\text { you } \mathrm{t}_{\mathrm{i}}\right]\right] & \mathrm{zhi} & \text { xiang }] \\ \text { not.exist } & \text { what } & \text { exist } & \text { GEN } & \text { place }\end{array}$ 'And (I) traveled around a place where there wasn't anything' (Zhuangzi $\bullet$ Yingdiwang)

Following this analysis, I suppose that only a certain type of in-situ $w h$-phrases in LAC, i.e., the second complement of ditransitive verbs, undergoes covert phrasal movement at LF, so these phrases are insensitive to the Intervention Effect that is supposed to be triggered by negation. Since these in-situ $w h$-items cannot move, they do not have any focus feature. Other $w h$-phrases, though supposed to stay in situ, undergo overt movement to a position c-commanding the negation triggered by blocking negators, so as to circumvent the Intervention Effect.

$W h$-items that are supposed to stay in situ yet have undergone obligatory or optional movement in LAC undergo feature movement and thus are sensitive to the Intervention Effect. As discussed previously, LF dependency of whnominals and $w h$-adverbials cannot cross NIBs, so $w h$-elements move to a position c-commanding the interveners, as in the second illustration of Examples (83a) and (83b), respectively. The first sentence in Example (83a) demonstrates that the whDP can move overtly (and actually, it has to, because of obligatory wh-fronting), which is a precondition for its movement past negation in the second sentence. This is also the case for $w h$-adverbials that are base-generated under negation. For $w h$-adverbials base-generated preverbally (Example [83b]) and postverbally 
(Example [83c]), they can undergo overt movement, and the diagnostic element 獨 $d u$ 'alone' indicates that the landing site is the Low focus position that is below negation. However, if the Q-binding is blocked by a c-commanding negative, the wh-adverbial has to rise to a higher landing site above negation, i.e., the High focus position (Example [83d]). That is to say, adverbial wh-phrases are subject to the blocking effect, analogous to $w h$-nominals. Examples $(83 \mathrm{e}-\mathrm{f})$ are cited as canonical examples, showing the base position of source adverbials, which is postverbal.

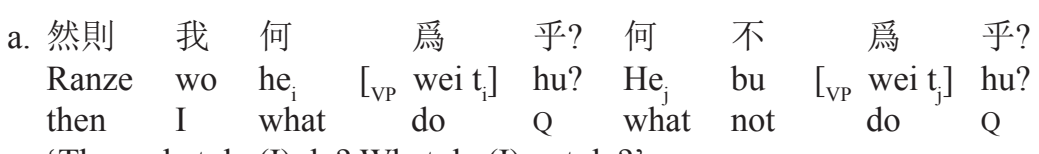

'Then what do (I) do? What do (I) not do?'

(Zhuangzi•Qiushui)

b. 先生獨何以說吾君乎?

Xiansheng du he $\mathrm{yi}_{\mathrm{j}}\left[{ }_{\mathrm{PP}} \mathrm{t}_{\mathrm{i}} \mathrm{t}_{\mathrm{j}} \mathrm{t}_{\mathrm{i}}\right]\left[\left[_{\mathrm{VP}}\right.\right.$ yue wu jun $]$ hu?

$\operatorname{sir}(\mathrm{you})$ alone what with please my lord $\mathrm{Q}$

'How did you alone please my lord?'

(Zhuangzi $\bullet$ Xuwugui)

c. 惡乎 用之? 用之 社 也

$\mathrm{Wu}_{\mathrm{i}} \quad \mathrm{hu}_{\mathrm{j}} \quad$ [VP $_{\mathrm{VP}}$ yong zhi $\left[\left[_{\mathrm{PP}} \mathrm{t}_{\mathrm{i}} \mathrm{t}_{\mathrm{j}} \mathrm{t}_{\mathrm{i}}\right]\right.$ ? [ [VP $_{\mathrm{VP}}$ Yong zhi] $\left[_{\mathrm{pp}}\right.$ she $]$ ye

where in use 3.OBJ use 3.OBJ shrine DECL

'In where (did he) use him? (He) used him in the shrine.'

(Gongyangzhuan $\bullet$ Xigong 19)

d. 夫子 焉 不 學?

Fuzi yan ${ }_{i}$ bu $\quad\left[{ }_{V P}\right.$ xue $]\left[{ }_{p p} t_{i} t_{i}\right]$ ?

Confucius where not study

'(From) where does Confucius not study?'

(Analects•Zizhang)

e. 孔子 學 於 老聑孟蘇譶靖叔

Kongzi [ ${ }_{\mathrm{VP}}$ xue $]$ [ $_{\mathrm{PP}}$ yu [Laodan Meng Sukui Jingshu]

Confucius study from Laodan Meng Sukui Jingshu

'Confucius studied from Laodan, Meng Sukui, and Jingshu.'

(Lüshichunqiu•Zhongchunji)

f. 柏矩 學 于 老聑

Boju [ ${ }_{\mathrm{VP}}$ xue $] \quad\left[_{\mathrm{pP}}\right.$ yu Laodan $]$

Boju study from Laodan

'Boju studied from Laodan.'

(Zhuangzi•Zeyang)

By contrast, as the second complement of ditransitive verbs nai/ruo/ru, wh-DPs are only allowed to undergo covert phrasal movement, so even if negation is present as a potential barrier for their Q-binding, these $w h$-DPs can (and have to) stay in situ (Examples [84a-d] [= Examples $(75 \mathrm{a}-\mathrm{d})]$ ). As a consequence, the negator, which is supposed to be an intervener, fails to create any blocking effect on its c-commanding in-situ $w h$-items, and these $w h$-DPs do not move across negation 
in Example (84). That is to say, the ban of feature movement determines that the configuration * wh-Neg-V-DP (derived from Neg-V-DP-wh) is never attested.

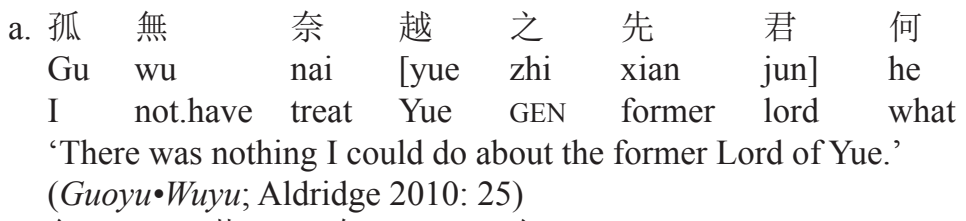

b. 無

$$
\text { 若 政 何 }
$$

$\mathrm{Wu}$ ruo zheng he

not.have treat ordinance what

'There is nothing (the ruler) can do about the ordinances.'

(Gиоуи $\bullet$ Jinyu 4)

$\begin{array}{llllll}\text { c. 亦 } & \text { 無 } & \text { 如 } & \text { 之 } & \text { 何 } & \text { 矣 } \\ \text { Yi } & \text { wu } & \text { ru } & \text { zhi } & \text { he } & \text { yi } \\ \text { also } & \text { not.have } & \text { treat } & \text { 3.OBJ } & \text { what } & \text { PERF }\end{array}$

'There is nothing (they) can do about it anymore.'

(Liji•Daxue)

$\begin{array}{llllll}\text { d. 吾 } & \text { 末 } & \text { 如 } & \text { 之 } & \text { 何 } & \text { 也已矣 } \\ \mathrm{Wu} & \mathrm{mo} & \mathrm{C}_{\mathrm{VP}} \text { ru } & \text { zhi } & \text { he }] & \text { yeyiyi } \\ \text { I } & \text { NEG } & \text { treat } & \text { 3.OBJ } & \text { what } & \text { SFP } \\ \text { 'I do not (know) how to treat him then.' } \\ \text { (Analects•Weilinggong) }\end{array}$

Since the obligatory $w h$-in-situ undergone covert phrasal movement circumvents the Intervention Effect of negation in LAC, it seems feasible that wh-phrases in Examples (84a-d) could have an interrogative meaning. However, this prediction is not borne out, because the $w h$-items are licensed as NPIs.

In modern Mandarin, there are $w h$-phrases that always stay in situ and are never subject to the Intervention Effect. I state that such in-situ $w h$-items undergo covert phrasal movement. The counterpart of the ditransitive verb 謂 wei 'call; speak of' in modern Mandarin is jiao 'call'. As mentioned earlier, when an interrogative $w h$-phrase functions as the second complement of 謂 wei in LAC, it either moves or remains in situ, depending on whether the first complement moves and whether the second complement is simplex. In Examples (85a-b), the wh-word 何 he moves to a preverbal position as the second complement, as it is simplex and the first complement has fronted to a preverbal position. In Examples (85c-e), however, the second complement does not move. In Examples (85c-d), although the second complement is a simplex $w h$-phrase he, the first complement does not move to a preverbal position, so the second complement cannot move either. In Example (85e), although the first complement has fronted to a preverbal position, the second complement is a complex $w h$-phrase, so it cannot move. As for jiao (the counterpart of wei in modern Mandarin), its second argument, i.e., the interrogative wh-DP, always moves covertly, regardless of whether the first complement moves 
or not (Examples [86b/a]); otherwise, an infelicitous sentence would be produced (Example [86c]).

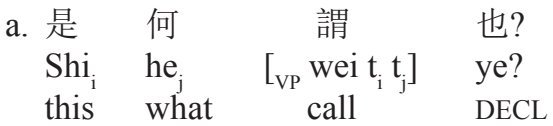

'How (do we) understand these?' (Lit. 'What [do we] call these?')

(Zuozhuan•Zhaogong 29)

b. 此言 何 謂 也

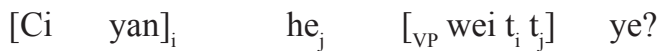

this sentence what call DECL

'How (do we) understand this sentence?' (Lit. 'What [do we] call this sentence?')

(Mengzi $\bullet$ Tengwengongshang)

c. 國謂君何?

Guo wei jun he?

state call lord what

'How does the state speak of the lord?' (Lit. 'What does the state call the lord?')

(Zuozhuan $\bullet$ Xigong 15)

d. 吾 獨 謂 先 王 何 乎?

$\mathrm{Wu}$ du wei [xian wang] he hu?

I alone tell former lord what Q

'What do I alone tell the former lord?'

(Lüshichunqiu•Jiqiuji)

e. 此所 謂 何 聲 也?

$\mathrm{Ci}_{\mathrm{i}}$ suo $\left[_{\mathrm{VP}}\right.$ wei $\mathrm{t}_{\mathrm{i}}$ [he sheng] $]$ ye?

this SUO call what sound DECL

'What sound (do we) call this?'

(Hanfeizi $\bullet$ Shiguo)

(86) a. Zhangsan [vp $_{\mathrm{vP}}$ jiao Lisi shenme]?

Zhangsan call Lisi what

'What does Zhangsan call Lisi?'

b. Zhangsan Lisi $i_{i} \quad\left[_{v p}\right.$ jiao $t_{i}$ shenme $?^{22}$

Zhangsan Lisi call what

'What does Zhangsan call Lisi?'

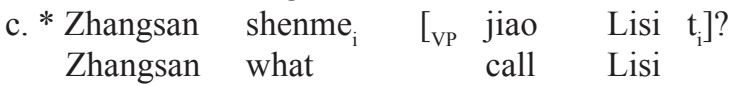

22 Example (86b) sounds more natural with a contrast:

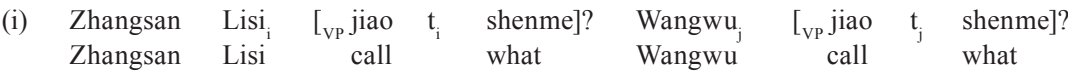

'What does Zhangsan call Lisi? What (does Zhangsan) call Wangwu?'

However, there is no way we can rescue the infelicity of Example (86c). 
Since, in modern Mandarin, it is impossible for a wh-DP to move overtly as the second object of the ditransitive verb jiao, there should not be any intervening effect. This prediction is borne out. As illustrated by Examples $(87 \mathrm{a}-\mathrm{b} / \mathrm{c})$, an interrogative wh-in-situ may follow a focus construction or negator, both of which are expected to be interveners in modern Mandarin and LAC, respectively, but neither element produces the blocking effect. In Example (87a), the subject Zhangsan is focalized and in Example (87b), the object Lisi is focalized, but neither focus construction blocks the Q-binding of the second argument shenme 'what'.
a. Lian
Zhangsan
dou $\left[_{\mathrm{VP}}\right.$ jiao
Lisi
shenme]?
even
Zhangsan
also
call Lisi
what
'What does even Zhangsan call Lisi?'

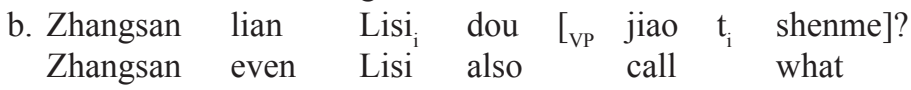
'What does Zhangsan call even Lisi?'

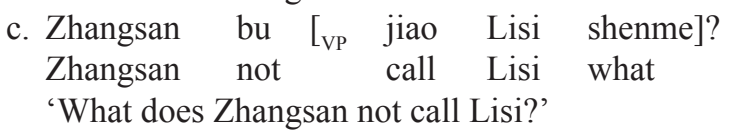

Similarly, in-situ wh-phrases in ordinary multiple questions in modern Mandarin also undergo covert phrasal movement at LF and hence are insensitive to focus interveners.
a. Zhangsan
zhidao shui
zai nali
mai-le
shenme
ma?
Zhangsan
know
who at
where
buy-ASP what
Q
'Does Zhangsan know who bought what (at) where?'

b. Zhangsan ye zhidao shui zai nali mai-le shenme ma? Zhangsan also know who at where buy-ASP what Q 'Does Zhangsan, too, know who bought what (at) where?'

c. Lian Zhangsan dou zhidao shui zai nali mai-le shenme ma? even Zhangsan also know who at where buy-ASP what Q 'Does even Zhangsan know who bought what (at) where?'

d. Zhiyou Zhangsan zhidao shui zai nali mai-le shenme ma? only Zhangsan know who at where buy-ASP what Q 'Does only Zhangsan know who bought what (at) where?'

By contrast, another ditransitive verb gei 'give' in modern Mandarin does not require obligatory $w h$-in-situ, and its $w h$-complement may stay in situ or front to a preverbal position (Example [89a/b]). So the second argument - an interrogative wh-phrase na-ben shu 'which book' - does not undergo covert phrasal movement and is subject to the Intervention Effect of focus. If the first complement of the ditransitive verb is focalized and fronts to a preverbal position, the Q-binding of the second complement, the which-phrase, is blocked by the focus construction (Example [89c]). Therefore, the wh-element has to move to a higher position preceding the focus-induced barrier, either in the "low inflectional phrase (IP) area" or in the CP domain (Examples [89d/e]). 


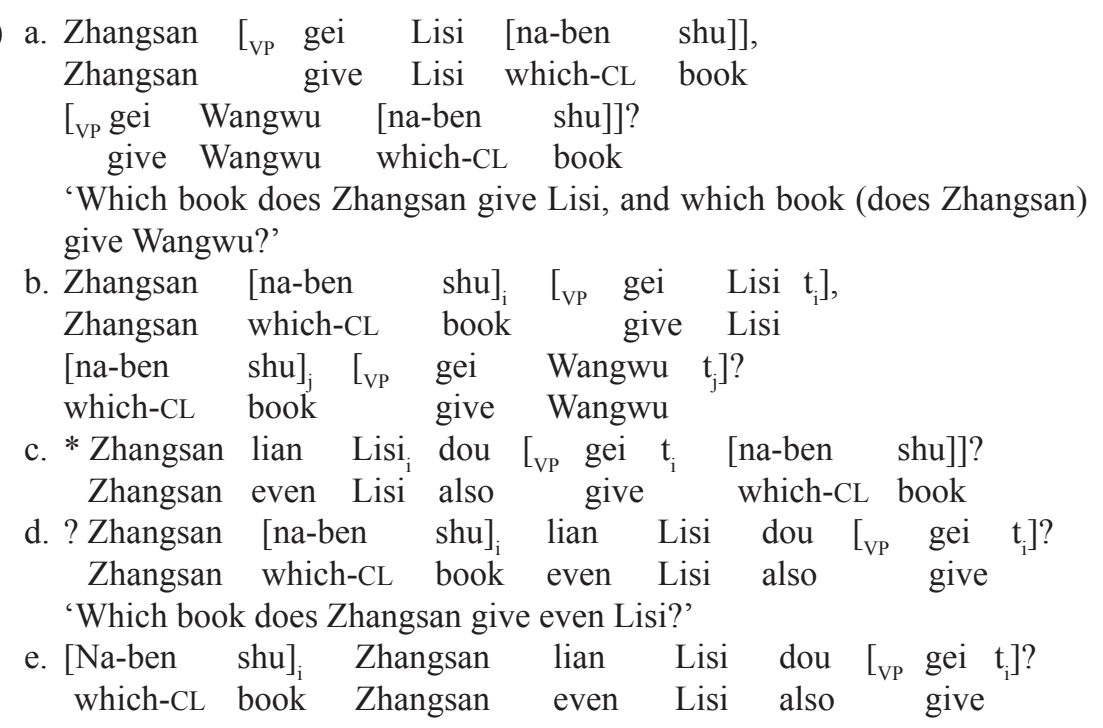

In terms of moved $w h$-items in LAC, they undergo covert phrasal movement, so they are immune from the Intervention Effect triggered by negation. In Example (90), despite the presence of a nominal quantifier 無 wu 'not exist; no' and the prediction that the licensing of the NPI 何 he should be sensitive to the Intervention Effect, the moved $w h$-word he appears in a position c-commanded by negation. Although he has fronted within an embedded clause, the licenser is still in a higher domain and the focalized $w h$-word is still below negation, which means that the intervening effect does not apply to this $w h$-item.
a. 何 不
樹
之 於 無
何 有
$\left[\begin{array}{lll}\text { he }_{\mathrm{i}} & \text { you } & \left.\mathrm{t}_{\mathrm{i}}\right]\end{array}\right]$ zhi
之 鄉?
$\mathrm{He}$ bu shu zhi yu [[wu
why not plant it
in not.exist
what exist
GEN place
'Why don't you plant it in a place where there isn't anything?'
(Zhuangzi $\bullet$ Xiaoyaoyou; Aldridge 2010: 26)
b. 而遊
Er you
無
何 有
之 鄉
CONJ travel.around not.exist what exist
[[wu $\left[\mathrm{he}_{\mathrm{i}}\right.$ you $\left.\left.\mathrm{t}_{\mathrm{i}}\right]\right]$
zhi xiang]
GEN place
'And (I) traveled around a place where there wasn't anything'
(Zhuangzi $\bullet$ Yingdiwang)

To summarize, in LAC, wh-phrases that always stay in situ, i.e., the second complements of ditransitive verbs nai/ruo/ru and wei, undergo covert phrasal movement, so they are insensitive to the Intervention Effect. Other wh-phrases that are supposed to stay in situ undergo feature movement and thus are subject to the Intervention Effect. Moved $w h$-phrases are parallel to the second argument of nai/ruo/ru and wei: they undergo covert phrasal movement and hence are not subject to the Intervention Effect. 
There is no denying the fact that the absence of the Intervention Effect in Example (85) may be caused by the noninterrogative interpretation of NPIs that lack Q-binding; that is to say, there is an overlap between the condition of compatibility with feature movement and that of interrogativity. Furthermore, the value of requiring a possibility of feature movement is doubtful if Example (90) is taken into consideration, in which the NPI $w h$-word has landed in a position c-commanded by the negative barrier. However, the absence of the blocking effect may be alternatively due to the noninterrogativeness of this NPI that does not create Q-binding, so the moved $w h$-word stays below negation without further rising.

To justify the requirement of feature movement without being affected by the condition of interrogativity, I refer to modern Mandarin. A negative preceding a $w h$-DP in LAC is only permitted to function as a negative operator licensing an NPI, which inevitably involves a noninterrogative interpretation. However, apart from licensing NPIs (Example [91a]), a negator in modern Mandarin may alternatively intervene between an interrogative in-situ $w h$-item and its licensor (Example [91b]), as negation is not necessarily a barrier for Q-binding in modern Mandarin. So, I use the Neg ... XP [+wh] configuration (Example [91b]) in modern Mandarin to validate the condition of feature movement, excluding the influence of noninterrogativeness. In Example (91c), shenme 'what' is c-commanded by a negator $b u$, but it is still interrogative, not licensed as an NPI. At the same time, as the second argument of the ditransitive verb jiao, shenme must remain in situ, even if being preceded by a focus expression; otherwise, an ungrammatical sentence would be generated (Example [91d]). The grammaticality of Focus ... XP [+wh] in Example (91c) indicates that the determining condition of this example is covert phrasal movement, rather than interrogativity.

a. Zhangsan bu jiao Lisi shenme.
Zhangsan not call Lisi what
'Zhangsan does not call Lisi anything.'
b. Zhangsan bu jia Lisi shenme?
Zhangsan not call Lisi what
'What does Zhangsan not call Lisi?'
c. Lian Zhangsan dou bu jiao Lisi shenme?
even Zhangsan also not call Lisi what
'What does not even Zhangsan call Lisi?'
d. * Shenme lian Zhangsan dou bu jiao Lisi t?
what even Zhangsan also not call Lisi

In LAC, since the obligatory $w h$-in-situ prohibits the $w h$-items from moving across negation yet negation is unarguably a barrier, we would expect ungrammaticality in a Neg-V-DP-wh construction. Nonetheless, the prediction is not borne out, and Neg-V-DP-wh is grammatical. Similarly, we would not expect a Foc-V-DP-wh structure in modern Mandarin, but it does exist. 
As can be seen, there are two types of $w h$-in-situ in both LAC and modern Mandarin: obligatory $w h$-in-situ and optional $w h$-in-situ. The obligatory $w h$-in-situ is strong enough to circumvent the Intervention Effect, yet the optional wh-in-situ is not. In LAC, the obligatory wh-in-situ - the second complement of ditransitive verbs nai/ruo/ru and wei - can circumvent the blocking effect of negation, allowing a $w h$-variable to be bound even remaining in situ. In modern Mandarin, likewise, the obligatory $w h$-in-situ - the second complement of the ditransitive verb jiao also blocks the Intervention Effect, so a $w h$-variable does not have to and must not front to an operator position. In contrast to this, the optional wh-in-situ is not strong enough to circumvent the blocking effect in LAC or modern Mandarin, as it is only an option, not a requirement. Consequently, the possibility of $w h$ staying in situ is suppressed by the presence of negation in LAC (Example [85]), and the wh-variable should move to the operator position. Likewise, in modern Mandarin, the option of $w h$-in-situ is not able to stop the Intervention Effect of focus, so an infelicitous sentence is generated in Example (89c), with a focus barrier intervening between a wh-variable and its Q-operator. The hierarchy of these two kinds of wh-in-situ and the Intervention Effect in both LAC and modern Mandarin is schematized as follows:

(92) Obligatory $w h$-in-situ $>$ The Intervention Effect $>$ Optional wh-in-situ

Stepanov's $(2001,2007)$ theory not only provides the reason why the second complement of ditransitive verbs must stay in situ, but it also accounts for the fact that the second argument of ditransitive verbs is not subject to the Intervention Effect. The second complement in ditransitive constructions receiving dative inherent Case is not a structural argument, so it is inert. Additionally, since this inherently Case-marked DP does not have an uninterpretable feature in its label that enables it to enter the structure by substitution, this $w h$-DP with dative Case has to enter the structure postcyclically by adjunction, hence being subject to the Late Adjunction Hypothesis. That is to say, the inherently Case-marked $w h$ is transparent and it misses out the cyclic part of the derivation. Due to the transparency of the $w h$-DP, overt movement, as a cyclic dependency, cannot apply to the $w h$-DP. The fact that the $w h$-DP is introduced too late when the dependency begins explains two derivational properties of an inherently Case-marked DP, which are always connected with each other: transparency and inertness. Since the second argument of a ditransitive verb is transparent for syntactic dependencies extending across it and it does not undergo overt movement, it is not subject to the Intervention Effect.

\subsection{Hierarchy of clausal positions}

The third condition for the Intervention Effect is that the landing sites of overt whmovement fit into a hierarchy of clausal positions, and even an application of the repair strategy never violates the relative ordering between topics and foci. Whfronting targets positions of different features, namely, topic positions and focus 
positions. Since these positions form a hierarchy in terms of their relative order, it appears that $w h$-fronting always fits into a certain hierarchy. Of course, the fact that $w h$-fronting targets positions with different features is independent of the fact that positions with Topic feature are located higher than those with Focus feature.

I suggest that topic positions are structurally more prominent than focus positions in LAC. First, this assumption can be supported by the comparison of the properties of constituents in these positions (Wang 2013). Second, following Hsu's (2008) analysis on object preposing in modern Mandarin, I assume that the relative order between internal topics and (internal) foci applies to LAC as well. Third, there is cross-linguistic evidence that topics are generally higher than foci.

The absence of the Intervention Effect from focus structures has been mentioned previously: focus expressions in LAC do not display the blocking effect. The lack of the Intervention Effect caused by focus coincides with the prediction made by the locality restriction. In Examples $(93 \mathrm{a}-\mathrm{c})$, the focused constituents are subjects; so, in order to circumvent the blocking effect, the wh-nominal and wh-adverbial have to rise from their base positions to a position preceding the focalized subjects, viz., some position in the clause-external left periphery. Since wh-movement in LAC is clause-internal (Aldridge 2006, Aldridge 2007, Aldridge 2010), preposing a $w h$-element to a position above TP is expected to be infeasible. Such a prediction is indeed borne out: the configuration of $* w h_{\mathrm{Foc}}-\left[{ }_{\mathrm{TP}} \cdots\right]$ is never attested in LAC, and the only exception I found is when a predicative $w h$-phrase functions as an external topic (Examples [93d-e]). Since the complex wh-phrase he zui/he 'what $\sin$ '/"what' (Examples [93a/b]) and the simplex wh-DP he 'what' in a predicate with a null preposition (Example [93c]) are all non-D-linked foci, they cannot front to the external topic position in Examples (93d-e). The focus constructions in Examples (93a-c) fail to function as barriers, and they permit whvariables to be bound even while remaining in c-commanded positions.
a. 先 君何
罪? 其
嗣
亦何
罪?
[Xian jun] [he zui]? [Q
si]
yi $\quad[$ he
zui]?
former lord what sin 3.GEN crown.prince also what sin 'What sin did the former lord (have)? What sin does his crown prince, too, (have)?'

(Zuozhuan •Wengong 7)
b. 太子 亦 何 如?
Taizi yi $\quad \mathrm{he}_{\mathrm{i}} \quad\left[_{\mathrm{VP}} \quad \mathrm{rut}_{\mathrm{i}}\right]$ ?
crown.prince also what be.like
'What is the crown prince, too, like?'
(Hanfeizi $\bullet$ Neichushuoxia)

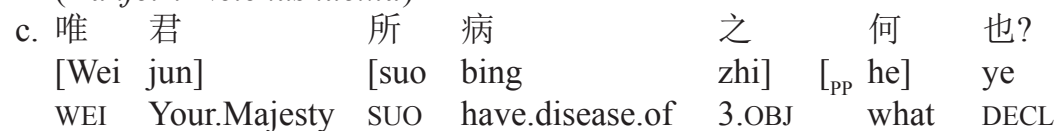

'(For) what is it only Your Majesty who has this disease?'

(Zhuangzi•Xuwugui) 


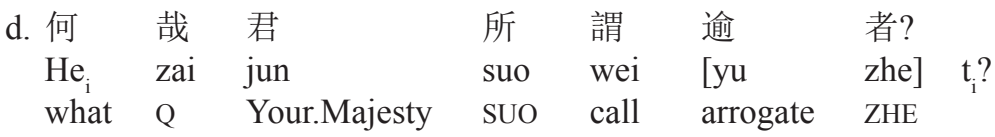

'What is the arrogation that Your Majesty meant?'

(Mengzi $\bullet$ Lianghuiwangxia)

e. 何哉, 爾所

$\mathrm{He}_{\mathrm{i}}$ zai, er suo wei [da zhe $] \mathrm{t}_{\mathrm{i}}$ ?

what Q you SUO call eminent ZHE

'What is the eminency that you meant?'

(Analects•Yanyuan)

The prediction made by the locality restriction is that a wh-phrase with [+Focus] feature cannot front to a position preceding a focalized subject; the surface order Foc-wh coincides with this prediction.

This proposal of locality restriction also coincides with the lack of any blocking effect from quantificational elements. Taking Example (94a) as an instance, the quantifier 皆 jie 'all' c-commands a wh-variable he that is raised from its VP-internal base position to a focused position triggered by obligatory whfronting. If LF wh-movement could not cross this quantifier and the repair strategy needed to be used, he would front to a position structurally even more prominent than this quantified element. Parallel to its counterpart dou in modern Mandarin, the quantifier 皆 jie 'all' in LAC only quantifies an NP to its left (Aldridge 2013). ${ }^{23}$ In Example (94a), the quantifier jie is supposed to be subject-oriented, so it immediately follows and quantifies over the (empty) subject, and hence it is situated higher than any focus position. To circumvent the Intervention Effect, he has to front to a position preceding jie (so neither the High nor the Low focus position is qualified), but he cannot intervene between the subject and the adjoined jie; so, this means that he has to target some position above the TP. Given the restriction of mere clause-internal movement on nontopical wh-constituents, the focused whword he cannot front to the left periphery, so no further $w h$-fronting has happened. As a consequence, this quantificational expression fails to induce any intervening effect. As for Example (94b), the focalized position between the subject 古之明 主 gu zhi ming zhu 'wise lords of ancient times' and the quantified structure 常 chang 'often' is occupied by a fronted VP, so there is no space for the wh-word he. Consequently, the quantificational expression fails to trigger any blocking effect, and the $w h$-item can stay in a position c-commanded by the quantifier.
a. 皆 何以
Jie he
稱人?
all what with
cheng ren]?
address person

'With what do (we) all address those people?'

(Gongyangzhuan •Huangong 15)

23 When (and only when) the object is a resumptive pronoun linked to a topic, 皆 jie quantifies to its right (Harbsmeier 1981). 


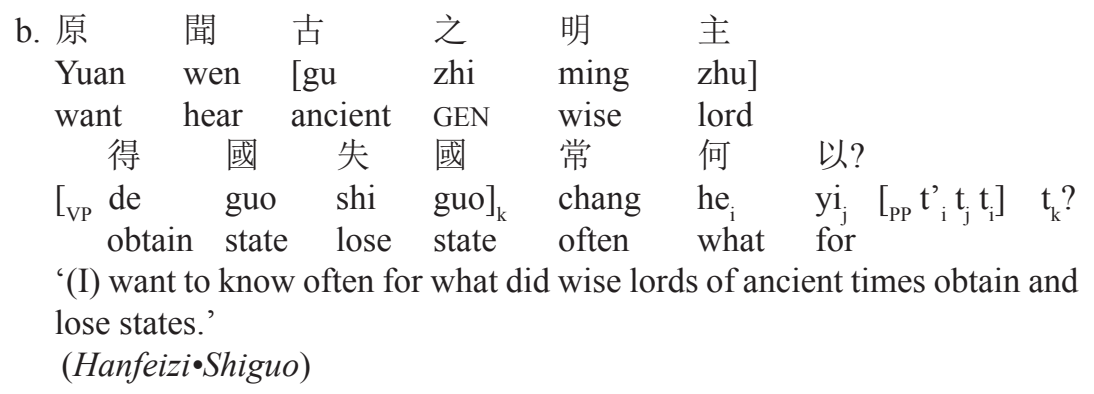

The proposal of locality restriction predicts that a wh-phrase cannot front cross a quantified subject, and this prediction is indeed borne out.

This condition concerning the clausal hierarchy applies to the data in modern Mandarin as well. The presence of the Intervention Effect of focus can be demonstrated by three kinds of focused constituents: arguments, adjuncts, and verb doubling constructions.

First, when subjects and goal arguments are focused, the c-commanded whDPs can move overtly to an operator position. The application of such a repair strategy does not violate the relative order between positions in the clause-external left periphery or that in the "low IP area". As discussed earlier, LAC normally does not permit wh-preposing to the CP area, unless the wh-phrases are predicates. Unlike LAC, modern Mandarin allows wh-movement to target the CP domain. That is to say, the grammaticality of $w h_{\mathrm{Top}}-\left[_{\mathrm{TP}} \ldots\right]$ ensures that a $w h$-argument can rise to a position preceding the focused subject. As shown in Examples (95-98), in which the subject is focalized by an also-phrase, even-phrase, only-phrase, and NPI, respectively, the c-commanded which-phrase variable rises to an external topic position above TP, preceding the focused subject.
a. ? Lili ye kan-le na-ben shu?
Lili also read-ASP which-CL book
b. Na-ben shu Lili ye kan-le? which-CL book Lili also read-ASP 'Which book did Lili, too, read?'
a. ?? Lian even Lili also read DE
Lili ye kan de
dong understand
na-ben
shu?
b. Na-ben shu lian

Lili 'Which book could even Lili understand?' kan de dong? read DE understand 'Which book could even Lili understand?'
a. ?* Zhiyou only
Lili kan-le na-ben shu? Lili read-ASP which-CL book
b. Na-ben shu zhiyou Lili kan-le? which-CL book only Lili read-ASP 'Which book did only Lili read?' 
(98)
a. * Shui ye kan bu
dong
na-ben shu?
who also read not
understand
which-CL book

b. Na-ben

shu

shui

ye

kan

bu dong?

which-CL book who also read not understand

'Which book could no one understand?'

(Kim 2002b: 626)

If the wh-phrases are not which-phrases, hence being non-D-linked foci, they can target either the internal or the external position. Unlike LAC, modern Mandarin allows the structure $w h_{\mathrm{Foc}}-\left[{ }_{\mathrm{TP}} \ldots\right]$. When the focus $w h$-phrase shenme 'what' is c-commanded by a focalized subject, shenme has to rise to the $\mathrm{CP}$ domain and occupy the external focus position (Examples [99-102]).

$\begin{array}{clll}\text { a. ? Lili } & y e & \text { chi-le } & \text { shenme? } \\ \text { Lili } & \text { also } & \text { eat-ASP } & \text { what } \\ \text { b. Shenme } & \text { Lili } & y e & \text { chi-le? } \\ \text { what } & \text { Lili } & \text { also } & \text { eat-ASP }\end{array}$

'What did Lili, too, eat?'
a. ?? Lian Lili ye chi-le shenme?
even Lili also eat-ASP what
b. Shenme lian Lili ye chi-le?
what even Lili also eat-ASP
'What did even Lili eat?'

(101)
a. ?* Zhiyou Lili chi-le shenme? only Lili eat-ASP what
b. Shenme zhiyou Lili chi-le? what only Lili eat-ASP
'What did only Lili eat?'

(102) a. * Shui ye bu chi shenme?
who also not eat
b. Shenme shui ye bu chi?
what who also not
'What did no one eat?'

Beck (2006) reports that which-phrases and wh-phrases like "what" and "who" do not behave uniformly in the presence of an intervener in modern Mandarin. According to judgments reported to Beck, there is a disagreement on whether instances such as Example (99a) are acceptable. Beck supposes that there is a dialect in modern Chinese in which which-phrases are sensitive to the Intervention Effect but wh-phrases such as "what" and "who" are not (Example [103] [=(32)]). In terms of the account for this phenomenon, it is correlated with the fact that wh-phrases such as "what" and "who" can undergo covert phrasal movement, yet which-phrases cannot. This phenomenon is similar to the superiority effects in English, in that "which" in English cannot move. 

a. \% Zhiyou
Lili
kan-le
shenme?
b. ?* Zhiyou
Lili
read-ASP
what
Lili
kan-le
na-ben
shu?
c. Na-ben
Lili
read-ASP
which-CL book
which-CL
shu
zhiyou
Lili
kan-le?
Lili
read-ASP

'Which book did only Lili read?'

(Beck 2006: 27)

According to native speakers' judgments I collected and my own intuition, ${ }^{24}$ whphrases such as "what" and "who" are indeed less sensitive to the Intervention Effect compared with which-phrases. This observation is particularly obvious in data concerning ye 'also': there is no much preferential distinction between "also ... what" (Example [99a]) and "what ... also" (Example [99b]), though the latter is slightly preferred by some native speakers. Nonetheless, as can be seen from Examples (98a/97a/96a/95a), the Intervention Effect on which-phrases weakens from an NPI/only-phrase/even-phrase to an also-phrase, which causes the consequence that the preferential difference between Examples (95a) and (95b) is expected to be trivial anyway. On the other hand, the judgmental preference between Examples (96a/97a/98a) involving an "even"-Focus, "only"-Focus, and NPI is more salient. Parallel to data involving which-phrases, examples concerning "what" also display the impact of the Intervention Effect in a more prominent way when the interveners are an even-phrase, only-phrase, and NPI (Examples [96/97/98]). Therefore, I conclude that $w h$-phrases like "what" are indeed subject to the Intervention Effect of focus, at least in some northern dialects of modern Chinese, including standard Mandarin. Nevertheless, the influence of the Intervention Effect on "what" might not (always) be as strong as that on which-phrases.

In addition, focalized goal arguments also help to prove the importance of the clausal hierarchy. Example (104a) is ungrammatical, as expected, because the Q-binding of the which-phrase "which book" is blocked by a goal argument licensed by a lian "even"-Focus. The D-linked which-phrase may front either to a preverbal position within the "low IP area" as an internal topic (Example [104b]) or into the CP domain as an external topic (Example [104c]); both movements produce felicitous sentences, because both types of topics are located higher than the foci.
a. * Zhangsan lian Lisi $_{i}$ dou Zhangsan even Lisi also
$\left[_{\mathrm{VP}}\right.$ gei give
$\mathrm{t}_{\mathrm{i}} \quad$ [na-ben shu]]? which-CL book
b. Zhangsan Zhangsan [na-ben shu $]_{j}$ lian lian Lis Lisi $_{i}$ dou 'Which book does Zhangsan give even to Lisi?'

24 There are 37 native speakers of Chinese, including myself, from Beijing and three other provinces in north China. 
c. $[\text { Na-ben shu }]_{j}$ Zhangsan lian Lisi $i_{i}$ dou [vP $_{V P}$ gei $\left.t_{i} t_{j}\right]$ ? which-CL book Zhangsan even Lisi also give 'Which book does Zhangsan give even to Lisi?'

When the wh-phrase that is c-commanded by a focalized goal argument is a non-D-linked focus, the $w h$-focus should move to an internal (Example [105b]) or external (Example [105c]) focus position; otherwise, ungrammaticality results (Example [105a]). As can be seen from Example (105b), when the information focus shenme 'what' fronts to a position in the clause-internal domain, the sentence with an information focus preceding an "even"-focus is felicitous; so, I postulate that the position accommodating information foci is structurally more prominent than that for "even" foci.
a. * Zhangsan lian
Lisi $_{i}$ dou $\left[_{\mathrm{VP}}\right.$ gei
$\mathrm{t}_{\mathrm{i}} \quad$ shenme]?
Zhangsan
even Lisi also give
what
b. Zhangsan shenme $_{j}$ lian
Lisi $_{i}$ dou
Zhangsan
what
even Lisi also
give

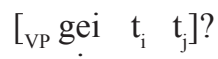
'What does Zhangsan give even to Lisi?'
c. Shenme ${ }_{j}$ Zhangsan lian Lisi ${ }_{i}$ do what Zhangsan even Lisi also
'What does Zhangsan give even to Lisi?'

Second, adjuncts focalized by a cleft shi ... de exhibit the intervening effect (Example [106a]), and which-phrases can move overtly from their base position to the internal/external topic position (Examples [106b/c]), parallel to those in Examples (106b/c). It is grammatical for a which-phrase to occupy a position preceding the focus, in that internal or external topics are located higher than foci.

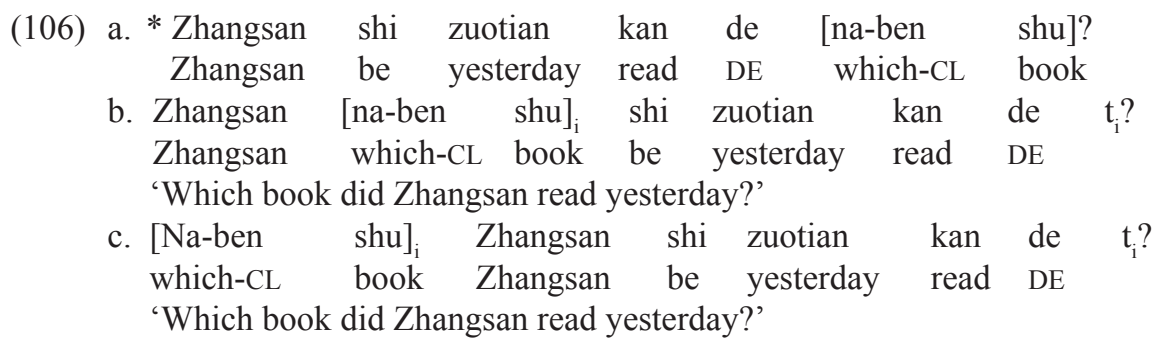

When the $w h$-phrase is a non-D-linked focus phrase like shenme 'what', similar to a which-phrase, it cannot stay in its base position (Example [107a]) but has to rise to the internal/external topic position (Examples $[107 \mathrm{~b} / \mathrm{c}]$ ). The grammaticality of Example (107b) indicates that the information focus "what" is situated in a position higher than the cleft shi ... de focus.

$\begin{array}{rlllll}\text { (107) a. * Zhangsan } & \text { shi } & \text { zuotian } & \text { kan } & \text { de } & \text { shenme? } \\ \text { Zhangsan } & \text { be } & \text { yesterday } & \text { read } & \text { DE } & \text { what }\end{array}$




$\begin{array}{llllll}\text { b. Zhangsan shenme }{ }_{i} \text { shi zuotian } & \text { kan de } & \mathrm{t}_{\mathrm{i}} \text { ? } \\ \text { Zhangsan what } & \text { be yesterday } & \text { read } & \text { DE } & \\ \text { 'What did Zhangsan read yesterday?' } & & & \\ \text { c. Shenme }{ }_{\mathrm{i}} \text { Zhangsan shi zuotian } & \text { kan } & \text { de } & \mathrm{t}_{\mathrm{i}} \text { ? } \\ \text { what Zhangsan be yesterday } & \text { read } & \text { DE } & \\ \text { 'What did Zhangsan read yesterday?' } & & & \end{array}$

Third, verb-doubling constructions indicate that the application of the repair strategy does not violate the relative order between foci or that between topics. The structures with verbal foci in Examples (108) and (109) (see below) are referred to as verb doubling lian ... dou and verb-doubling cleft, resepectively, which have the same internal syntax as regular lian ... dou (semantically equivalent to even) and cleft constructions, respectively (Cheng and Vicente 2013).

Examples involving the verb-doubling lian ... dou "even"-Focus structure demonstrate that there is a relative order between internal foci, and this order is never challenged. LF movement of the information focus "what" in Example (108a) is blocked by the verb-doubling lian ... dou construction, so the information focus rises to a higherposition(Examples [108b/c]). The possibility of fronting of the information focus over the "even"-Focus in Example(108b) indicates that in modern Mandarin, an information focus occupies a more prominent position than a verb-doubling "even"Focus construction.

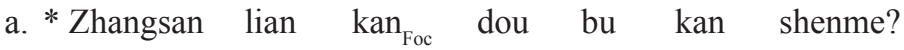 Zhangsan even read also not read what $\begin{array}{lllllll}\text { b. Zhangsan shenme } & \text { lian } \text { kan }_{\text {Foc }} \text { dou bu kan } t_{i} \text { ? } \\ \text { Zhangsan } & \text { what } & \text { even read also not read }\end{array}$ what Zhangsan even read also not read
'As for reading, what does Zhangsan not even read?'

As for verb-doubling clefts, they illustrate that external topics in the $\mathrm{CP}$ domain observe the clausal hierarchy as well. Verb-doubling clefts also act as barriers for LF wh-movement; so, in-situ $w h$-items cannot stay in their base position (Example [109a]). However, although the which-phrase moves overtly to the left periphery in both Examples (109c) and (109b), the grammatical/ ungrammatical asymmetry between these two examples implies that there is an ordering restriction: a discourse topic (the which-phrase) must precede a verbal (contrastive) topic (Cheng and Vicente 2013). This locality constraint accounts for the ungrammaticality of Example (109b) even with the wh-variable located higher than the intervener.

$\begin{array}{rlllll}\text { (109) a. }{ }^{*} \mathrm{Kan}_{\text {Top}}, & \text { Zhangsan } & \text { shi } & \text { kan-guo }_{\text {ooc }} & {[\text { na-ben }} & \text { shu], } \\ \text { read } & \text { Zhangsan } & \text { be } & \text { read-EXP } & \text { which-CL } & \text { book }\end{array}$




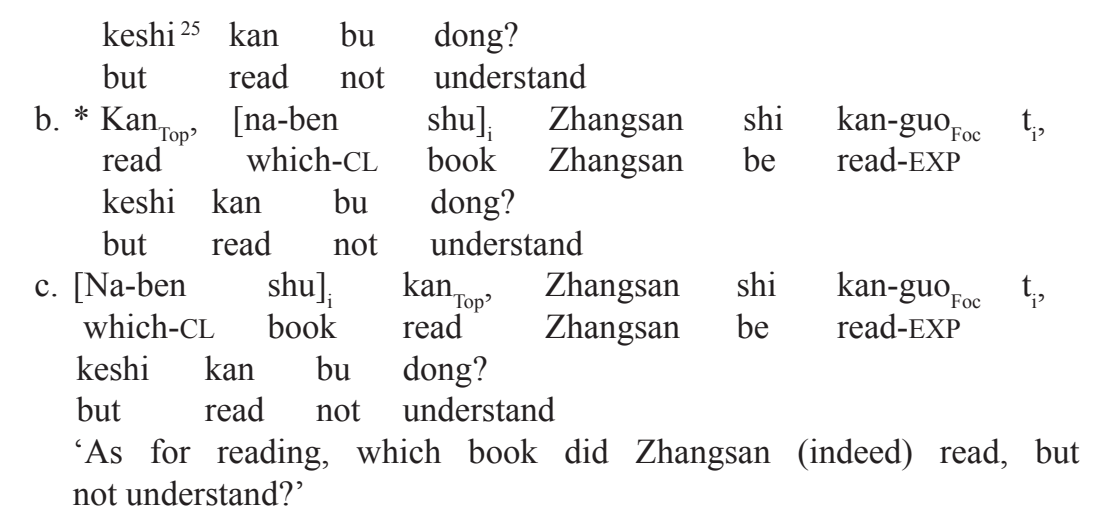

Additionally, reason wh-adverbials are also subject to the Intervention Effect of focus in modern Mandarin.

First, if a goal argument is focused by the lian ... dou "even"-Focus, the Q-binding between the wh-adverbial weishenme 'reason-why' and its Q-operator is blocked by the "even"-Focus. In the canonical order, weishenme intervenes between the subject and the ditransitive verb gei 'give' (Example [110a]). If the goal argument is focalized, leaving weishenme in its base position following the focus phrase gives rise to an ungrammatical sentence, as in Example (110b). To circumvent the blocking effect, the $w h$-adverbial has to land in a position preceding the focus construction (Example [110c]).
a. Zhangsan weishenme ${ }_{\mathrm{VP}}$ gei Lisi [yi-ben shu $]$ ? Zhangsan why give Lisi 1-CL book
'Why does Zhangsan give Lisi a book?'
b. * Zhangsan lian Lisi dou weishenme $\left[_{\mathrm{VP}}\right.$ gei $\mathrm{t}_{\mathrm{i}}$ [yi-ben shu]]? Zhangsan even Lisi also why give 1-CL book
c. Zhangsan weishenme ${ }_{j}$ lian Lisi $_{i}$ dou $t_{j} \quad{ }_{\mathrm{VP}}$ gei $\mathrm{t}_{\mathrm{i}}$ [yi-ben shu]]? Zhangsan why even Lisi also give 1-CL book 'Why does Zhangsan give a book even to Lisi?'

Second, a focused theme argument in a ditransitive construction can impose the Intervention Effect on a $w h$-adverbial. In a canonical sentence (Example [111a]), the wh-adverbial weishenme 'reason-why' intervenes between the subject and the negator $b u$. When the theme argument shu is focalized by the "even"-Focus and thus is fronting to a position preceding the $w h$-adverbial, the sentence becomes bad (Example [111b]). To realize Q-binding between the wh-adverbial and its Q-operator, which is blocked by the focus theme argument, the wh-adverbial has to move across the focus-induced barrier, as in Example (111c).

25 The appending keshi (=danshi, buguo, or raner) 'but' conveys an adversative implicature triggered by verb-doubling clefts in modern Mandarin (Cheng and Vicente 2013). 
(111)
a. Zhangsan
weishenme bu
$\left[_{\mathrm{VP}}\right.$ gei Lisi
shu]?
Zhangsan
why
not
give Lisi
book
'Why does Zhangsan not give Lisi books?'
b. * Zhangsan lian $\mathrm{shu}_{\mathrm{i}}$ dou weishenme bu $\left[_{\mathrm{VP}}\right.$ gei Lisi $\left.\mathrm{t}_{\mathrm{i}}\right]$ ? Zhangsan even book also why not give Lisi
c. Zhangsan weishenme ${ }_{j}$ lian shu $_{\mathrm{i}}$ dou $\mathrm{t}_{\mathrm{j}}$ bu $\left[_{\mathrm{VP}}\right.$ gei Lisi $\left.\mathrm{t}_{\mathrm{i}}\right]$ ? Zhangsan why even book also not give Lisi
'Why does Zhangsan give not even books to Lisi?'

Therefore, the seemingly paradoxical observation that focus constructions display the Intervention Effect in modern Mandarin but not in LAC may be correlated with locality constraints on wh-constituents. In modern Mandarin, wh-DPs and wh-adverbials moving overtly to higher positions can fit into the hierarchy of clausal positions, whereas those in LAC would violate the relative order among topics and foci if they are raised to a position preceding the focused elements.

\section{Conclusion}

The observation that negation triggers the Intervention Effect in LAC is disparate from that in modern Mandarin, in which the Intervention Effect is caused by focus expressions. In LAC, preposed wh-phrases, including arguments and adverbials, as well as $w h$-items that have the option to stay in situ, are subject to the Intervention Effect triggered by negation. As a consequence, these wh-phrases have to move to a focus position above negation, which is expected to accommodate "high" reason adverbials exclusively. I propose that the Intervention Effect in LAC is a consequence of Q-binding as feature movement of [wh], interacting with fronting into the hierarchy of clause-internal positions driven by [Topic] or [Focus] features. Nonetheless, focus or quantificational expressions fail to impose any blocking effect in LAC. I also propound that for the Intervention Effect to take place in both LAC and modern Mandarin, three obligatory requirements must be satisfied: interrogativity of $w h$-items, the possibility of feature wh-movement, as well as a hierarchy of clausal positions.

\section{Acknowledgments}

I am grateful for the insightful comments offered by anonymous peer reviewers of Studies in Chinese Linguistics - their expertise has improved this research in innumerable ways. I am also thankful for my native-Mandarin-speaking friends and colleagues who have made grammaticality judgment on Mandarin examples cited in this paper.

\section{Primary sources}

CCL Corpus [Electronic Corpus of Chinese Texts]

http://ccl.pku.edu.cn:8080/ccl_corpus/

Center for Chinese Linguistics, Peking University, Beijing, China 
BCC Corpus [Electronic Corpus of Chinese Texts]

http://bcc.blcu.edu.cn/zh/cid/5

BLCU Corpus Centre, Beijing Language and Culture University, Beijing, China

Hanji Dianzi Wenxian [Electronic Corpus of Chinese Texts]

http://hanji.sinica.edu.tw

Institute of Linguistics, Academic Sinica, Taipei, Taiwan

\section{References}

Aldridge, Edith. 2006. VP-internal quantification in old Chinese. In Redouane Djamouri \& Rint Sybesma (eds.), Chinese linguistics in Budapest, 1-15. Paris: Ecole des Hautes Etudes en Sciences Sociales, Centre de Recherches Linguistiques sur l'Asie Orientale.

Aldridge, Edith. 2007. $W h$-indefinites and their relation to $W h$-in-situ. In Malcolm Elliott, James Kirby, Osamu Sawada, Eleni Staraki \& Suwon Yoon (eds.), Proceedings of the 43rd Meeting of the Chicago Linguistics Society, vol. 2, 139153. Chicago: Chicago Linguistic Society.

Aldridge, Edith. 2009. The old Chinese determiner zhe. In Paola Crisma \& Giuseppe Longobardi (eds.), Historical syntax and linguistic theory, 233-248. New York: Oxford University Press.

Aldridge, Edith. 2010. Clause-internal wh-movement in Archaic Chinese. Journal of East Asian Linguistics 19(1). 1-36.

Aldridge, Edith. 2013. Survey of Chinese historical syntax: Pre-Archaic and Archaic Chinese. Language and Linguistics Compass 7(1). 58-77.

Aoun, Joseph \& Yen-Hui Audrey Li. 1993. Syntax of scope. Cambridge, MA: MIT Press.

Beck, Sigrid. 1996a. Quantified structures as barriers for LF movement. Natural Language Semantics 4(1). 1-56.

Beck, Sigrid. 1996b. Wh-constructions and transparent logical form. Tübingen, Baden-Württemberg: Universität Tübingen dissertation.

Beck, Sigrid. 2006. Intervention effects follow from focus interpretation. Natural Language Semantics 14(1). 1-56.

Beck, Sigrid \& Shin-Sook Kim. 1997. On wh- and operator scope in Korean. Journal of East Asian Linguistics 6(4). 339-384.

Cheng, Lisa Lai-Shen. 1995. On dou-quantification. Journal of East Asian Linguistics 4(3). 197-234.

Cheng, Lisa Lai-Shen. 2009. Wh-in-situ, from the 1980s to now. Language and Linguistics Compass 3(3). 767-791.

Cheng, Lisa Lai-Shen \& Luis Vicente. 2013. Verb doubling in Mandarin Chinese. Journal of East Asian Linguistics 22(1). 1-37.

Chomsky, Noam. 1981. Lectures on government and binding. Dordrecht: Foris.

Chomsky, Noam. 1986. Barriers. Cambridge, MA: MIT Press.

Chomsky, Noam. 2000. Minimalist inquiries: The framework. In Roger Martin, David Michaels, Juan Uriagereka \& Samuel Jay Keyser (eds.), Step by step: Essays 
on minimalist syntax in honor of Howard Lasnik, 89-155. Cambridge, MA: MIT Press.

Chomsky, Noam. 2001. Beyond explanatory adequacy. Ms.: MIT.

Djamouri, Redouane. 2009. Cong jiagu, jinwen kan "yi” yufahua de guocheng [Development of "yi" in the oracle bones and bronze inscriptions]. Zhongguo Yuwen [Studies of the Chinese language] 1. 3-9.

Feng, Shengli. 1996. Prosodically constrained syntactic changes in Early Archaic Chinese. Journal of East Asian Linguistics 5(4). 323-371.

Guerzoni, Elena. 2006. Intervention effects on NPIs and feature movement: Towards a unified account of intervention. Natural Language Semantics 14(4). 359-398.

Guo, Xiliang. 1998. Jieci "yi" de qiyuan he fazhan [Origin and development of "yi"]. Guhanyu Yanjiu [Research in ancient Chinese] 38(1). 1-5.

Hale, Mark. 1998. Diachronic syntax. Syntax 1(1). 1-18.

Hale, Mark. 2007. Historical linguistics: Theory and method. Oxford: Blackwell.

Harbsmeier, Christoph. 1981. Aspects of classical Chinese syntax. London: Curzon Press.

Haspelmath, Martin. 1997. Oxford studies in typology and linguistic theory. Oxford: Clarendon.

Hsu, Yu-Yin. 2008. The sentence-internal topic and focus in Chinese. In Marjorie K.M. Chan \& Hana Kang (eds.), Proceedings of the 20th North American Conference on Chinese Linguistics (NACCL-20), 635-652. Columbus: Ohio State University.

Huang, C.-T. James. 1982. Logical relations in Chinese and the theory of grammar. Cambridge, MA: Massachusetts Institute of Technology dissertation.

Huang, C.-T. James. 1994. Logical form. In Gert Webelhuth (ed.), Government and binding theory and the minimalist program, 127-175. Oxford: Blackwell.

Jackendoff, Ray. 1972. Semantic interpretation in generative grammar. Cambridge, MA: MIT Press.

Jin, Dawei. 2017. A semantic account of the intervention effects in Chinese whyquestions. In Helle Hvid Hansen, Sarah E. Murray, Mehrnoosh Sadrzadeh \& Henk Zeevat (eds), Logic, Language, and Computation: TbiLLC 2015. (Lecture Notes in Computer Science, vol. 10148), 66-88. Berlin: Springer.

Kim, Shin-Sook. 2002a. Focus matters: Two types of intervention effect. Paper presented at The 21st West Coast Conference on Formal Linguistics, University of California, Santa Cruz, 5-7 April.

Kim, Shin-Sook. 2002b. Intervention effects are focus effects. In Noriko Akatsuka \& Susan Strauss (eds.), Japanese/Korean linguistics 10, 615-628. Stanford, CA: Center for the Study of Language and Information.

Kim, Shin-Sook. 2005. Focus intervention effects in questions. Paper presented at the Third Workshop on Theoretical East Asian Linguistics (TEAL-3), Harvard University, 22-23 July.

Kim, Shin-Sook. 2006. Intervention effects in questions. Frankfurt: University of Frankfurt dissertation. 
Ko, Heejeong. 2005. Syntax of why-in-situ: Merge into [Spec, CP]. Natural Language \& Linguistic Theory 23(4). 867-916.

Lahiri, Utpal. 1998. Focus and negative polarity in Hindi. Natural Language Semantics 6(1). 57-123.

Li, Haoze \& Candice Chi-Hang Cheung. 2015. Focus intervention effects in Mandarin multiple wh-questions. Journal of East Asian Linguists 24(4). 361-382.

Lin, Jo-Wang. 1992. The syntax of zenmeyang 'how' and weishenme 'why' in Mandarin Chinese. Journal of East Asian Linguistics 1(3). 293-331.

Linebarger, Marcia. 1987. Negative polarity and grammatical representation. Linguistics and Philosophy 10. 325-387.

Meisterernst, Barbara. 2008. Modal verbs in Han period Chinese Part I: The syntax

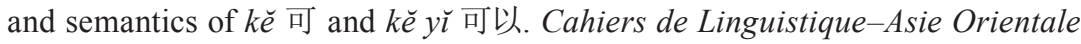
37(1). 85-120.

Noh, Eun-Ju. 2011. A pragmatic approach to intervention effect sentences in Korean: Focus, presupposition, and metarepresentation. Linguistic Research 28(1). 179-197.

Pesetsky, David. 1987. Wh-in-situ: Movement and unselective binding. In Eric Reuland \& Alic Meulen (eds.), The representation of (in)definiteness, 98-129. Cambridge, MA: MIT Press.

Pesetsky, David. 2000. Phrasal movement and its kin. Cambridge, MA: MIT Press.

Peyraube, Alain. 1996. Recent issues in Chinese historical syntax. In C.-T. James Huang \& Y-H. Audrey Li (eds.), New horizons in Chinese linguistics, 161-214. Dordrecht: Kluwer.

Peyraube, Alain. 1997. On word order in Archaic Chinese. Cahiers de Linguistique Asie Orientale 26(1). 3-20.

Prince, Ellen. 1981. Toward a taxonomy of given/new information. In Peter Cole (ed.), Radical pragmatics, 223-255. New York: Academic Press.

Pulleyblank, Edwin G. 1995. Outline of classical Chinese grammar. Vancouver: University of British Columbia Press.

Rizzi, Luigi. 2001a. On the position "Int(errogative)" in the left periphery of the clause. Current Studies in Italian Syntax 14. 267-296.

Rizzi, Luigi. 2001b. Relativized minimality effects. In Mark. Baltin \& Chris Collins (eds.), The handbook of contemporary syntactic theory, 89-110. Oxford: Blackwell.

Rizzi, Luigi. 2004. Locality and left periphery. In Adriana Belletti (ed.), Structures and beyond: The cartography of syntactic structures, vol. 3, 104-131. New York: Oxford University Press.

Schwarzschild, Roger. 1999. GIVENness, Avoid F, and other constraints on the placement of accent. Natural Language Semantics 7(2). 141-177.

Soh, Hooi Ling. 2005. Wh-in-situ in Mandarin Chinese. Linguistic Inquiry 36(1). 143-155.

Stepanov, Arthur. 2001. Late adjunction and minimalist phrase structure. Syntax 4(2). 94-125. 
Stepanov, Arthur. 2007. The end of CED? Minimalism and extraction domains. Syntax 10(1). 80-126.

Stepanov, Arthur \& Wei-Tien Dylan Tsai. 2008. Cartography and licensing of whadjuncts: A cross-linguistic perspective. Natural Language \& Linguistic Theory 26(3). 589-638.

Tomioka, Satoshi. 2007. Pragmatics of LF intervention effects: Japanese and Korean Wh-interrogatives. Journal of Pragmatics 39(9). 1570-1590.

Tsai, Wei-Tien Dylan. 1994. On economizing the theory of A-bar dependencies. Cambridge, MA: Massachusetts Institute of Technology dissertation.

Tsai, Wei-Tien Dylan. 1999. On lexical courtesy. Journal of East Asian Linguistics 8(1). 39-73.

Wang, Aiqing. 2013. Object preposing in late archaic Chinese. York Papers in Linguistics 13. 70-98.

Wang, Aiqing. 2015. The intervention effect of negation on wh-adverbials in Late Archaic Chinese. In Alison Biggs, Man Li, Aiqing Wang \& Cong Zhang (eds.), Proceedings of the Second Asian and European Linguistic Conference, 160-172. Newcastle: Newcastle University Library.

Wang, Aiqing. 2016. Clause-internal preposing in Late Archaic Chinese. York: University of York dissertation.

Wang, Li. 1981 [1962]. Zhongguo yuyanxue shi [History of Chinese linguistics]. Taiyuan: Shanxi People's Publishing House.

Wang, Li. 2004 [1958]. Hanyu shigao [History of Chinese]. Beijing: Zhonghua Shuju.

Yang, Barry Chung-Yu. 2007. Intervention effect, wh-movement, and focus. UST Working Papers in Linguistics 3. 95-108.

Yang, Barry Chung-Yu. 2008. Intervention effects and the covert component of grammar. Hsinchu: National Tsing Hua University dissertation.

Yang, Barry Chung-Yu. 2012. Intervention effects and wh-construals. Journal of East Asian Linguistics 21. 43-87.

Yang, Barry Chung-Yu. 2015. Locating wh-intervention effects at CP. In Wei-Tien Dylan Tsai (ed.), The cartography of Chinese syntax, 153-186. Oxford \& New York: Oxford University Press.

Yap, Foong Ha, Jiao Wang \& Charles Tsz-Kwan Lam. 2010. Clausal integration and the emergence of mitigative and adhoratative sentence-final particles in Chinese. Special issue on stance phenomena in Chinese: Diachronic, discourse and processing perspectives. Taiwan Journal of Linguistics 8(2). 63-86.

Zhou, Fagao. 1959. Zhongguo gudai yufa [Historical grammar of ancient Chinese]. Taipei: Academia Sinica Institute of History and Philology.

\section{Aiqing Wang}

Mailing address: Department of Modern Languages and Cultures, University of Liverpool, 1-7 Abercromby Square, Liverpool, L69 7WY, UK

Email:

Received: Aiqing.Wang@liverpool.ac.uk

Accepted: September 9, 2019 June 30, 2020 


\title{
干預作用在先秦漢語後期與現代漢語中的體現
}

\author{
王艾青
}

利物浦大學

\section{提要}

本文旨在研究干預作用 (Intervention Effect) 在先秦漢語後期與現代漢語中的體 現。在先秦漢語後期, 否定結構對疑問短語 (wh-phrase) 表現出干預作用。受否定 結構影響的疑問短語可分為兩類：一類是本應位移至否定結構之下並佔據較低焦 點 (focus) 位置的疑問論元 (argument) 和狀語 (adverbial), 另一類是可停留在原位 (in situ) 的疑問論元和狀語。由於否定結構形成障礙, 受成分統治 (c-commanded) 的疑問短語必須提升 (raise) 至否定結構之上的較高焦點位置, 從而規避該干預 作用。先秦漢語後期的干預作用是由疑問綁定 (Q-binding) 作為疑問的特徵位移 (feature movement) 引發的, 並與由話題 (topic) 或焦點特徵決定的位移位置等級 (hierarchy) 相互作用。與否定結構相反, 焦點或量化 (quantificational) 結構在先秦 漢語後期未表現出干預作用。在現代漢語中, 對疑問論元表現出干預作用的是焦 點結構, 而非否定或量化結構; 而僅有否定結構對表時間的疑問狀語表現出干預 作用。在先秦漢語後期, 干預作用的實現必須滿足三項條件：疑問結構的疑問性 (interrogativity)、特徵位移的可能性、位移位置的等級。儘管干預作用在先秦漢語後 期和現代漢語中的觸發因素不同, 但其須滿足的三項條件是一致的。此外, 先秦漢 語後期和現代漢語的數據均證明了特徵位移相關研究的合理性。

\section{關鍵詞}

干預作用，疑問短語，先秦漢語後期，現代漢語，句法學 